\title{
Nanocasting nanoporous inorganic and organic materials from polymeric bicontinuous microemulsion templates
}

\author{
Brad H Jones ${ }^{1}$ and Timothy P Lodge ${ }^{1,2}$
}

Ternary blends of two homopolymers and a diblock copolymer can self-assemble into interpenetrating, three-dimensionally continuous networks with a characteristic length scale of $\sim 100 \mathrm{~nm}$. In this review, we summarize our recent work demonstrating that these equilibrium fluid phases, known as polymeric bicontinuous microemulsions $(B \mu E)$, can be designed as versatile precursors to nanoporous materials having pores with uniform sizes of $\sim 100 \mathrm{~nm}$. As a model system, nanoporous polyethylene $(\mathrm{PE})$ is derived from $\mathrm{B} \mu \mathrm{Es}$ composed entirely of polyolefins. This monolithic material is then used as a template in the synthesis of other nanoporous materials for which structural control at the $\mathrm{nm}$ scale has traditionally been difficult to achieve. These materials, which include a high-temperature ceramic, polymeric thermosets and a conducting polymer, are produced by a simple nanocasting process, providing an inverse replica of the PE template. The PE is further used as a template for the production of hierarchically structured inorganic and polymeric materials by infiltration of mesostructured compounds into its pore network. The work described herein represents an unprecedented suite of nanoporous materials with well-defined pore structures prepared from a single PE template. They are anticipated to have potential application in diverse technological areas, including catalysis, separations and electronic devices.

Polymer Journal (2012) 44, 131-146; doi:10.1038/pj.2011.136

Keywords: ceramics; hierarchically structured materials; nanocasting; poly(3,4-ethylenedioxythiophene); polyethylene; polymeric bicontinuous microemulsions; thermosets

\section{INTRODUCTION}

Materials comprising two or more phases assembled in periodic, nanoscale structures represent a substantial area of current research. In particular, bicontinuous structures are distinctive arrangements where each phase is independently continuous in three dimensions. If one of the phases is removed, the resultant material will contain a three-dimensionally interconnected network of pores with inherently high surface area. Such materials are key to many applications, including catalysis, ${ }^{1}$ separations and drug delivery, ${ }^{2}$ electronic devices ${ }^{3}$ and gas storage. ${ }^{4}$ Therefore, there is a strong motivation to develop new or improved strategies for the synthesis of bicontinuous, nanoporous materials with well-defined pore shapes and sizes.

Nanocasting, a nanoscale extension of traditional casting or molding techniques, has emerged as a powerful tool for precisely manipulating nanostructure. ${ }^{5}$ A solid, nanoporous material or a nanostructured array of objects containing a prescribed void space is used as a template. The void space is infiltrated with a liquid precursor to the desired product. Through an external stimulus such as temperature or $\mathrm{pH}$ the precursor is converted to the desired product. Finally, the template is selectively removed by chemical or thermal means, and the infiltrated product is generated, possessing the inverse structure of the template. These steps are shown schematically in Figure 1.

Several factors dictate whether a particular combination of product and template can be successfully nanocasted. For a liquid precursor to spontaneously infiltrate a nanoporous template, a positive capillary pressure must exist; this implies that the contact angle of the precursor with the pore walls must be less than $90^{\circ} .7$ Thus, the surface chemistry of the template is a critical consideration in nanocasting, as templates with specific pore wall functionality may resist infiltration by a substantially incompatible liquid. Another important concern is the relative stability of the template and product materials. The template must be insoluble in, or otherwise unaffected by, the infiltrated precursor, and must survive the conditions necessary for conversion to product. Furthermore, a route must exist by which the template can be selectively removed or degraded, without disturbing the structural integrity of the product. Then, the product must have sufficient connectivity and mechanical strength to support the framework defined by the inverse of the template. These aspects are controlled to a large degree by intrinsic properties, for example, modulus, and the

${ }^{1}$ Department of Chemical Engineering and Materials Science, Minneapolis, MN, USA and ${ }^{2}$ Department of Chemistry, University of Minnesota, Minneapolis, MN, USA Correspondence: Professor TP Lodge, Department of Chemistry, University of Minnesota, Minneapolis, MN 55455, USA.

E-mail: lodge@umn.edu

Received 20 October 2011; accepted 1 November 2011 


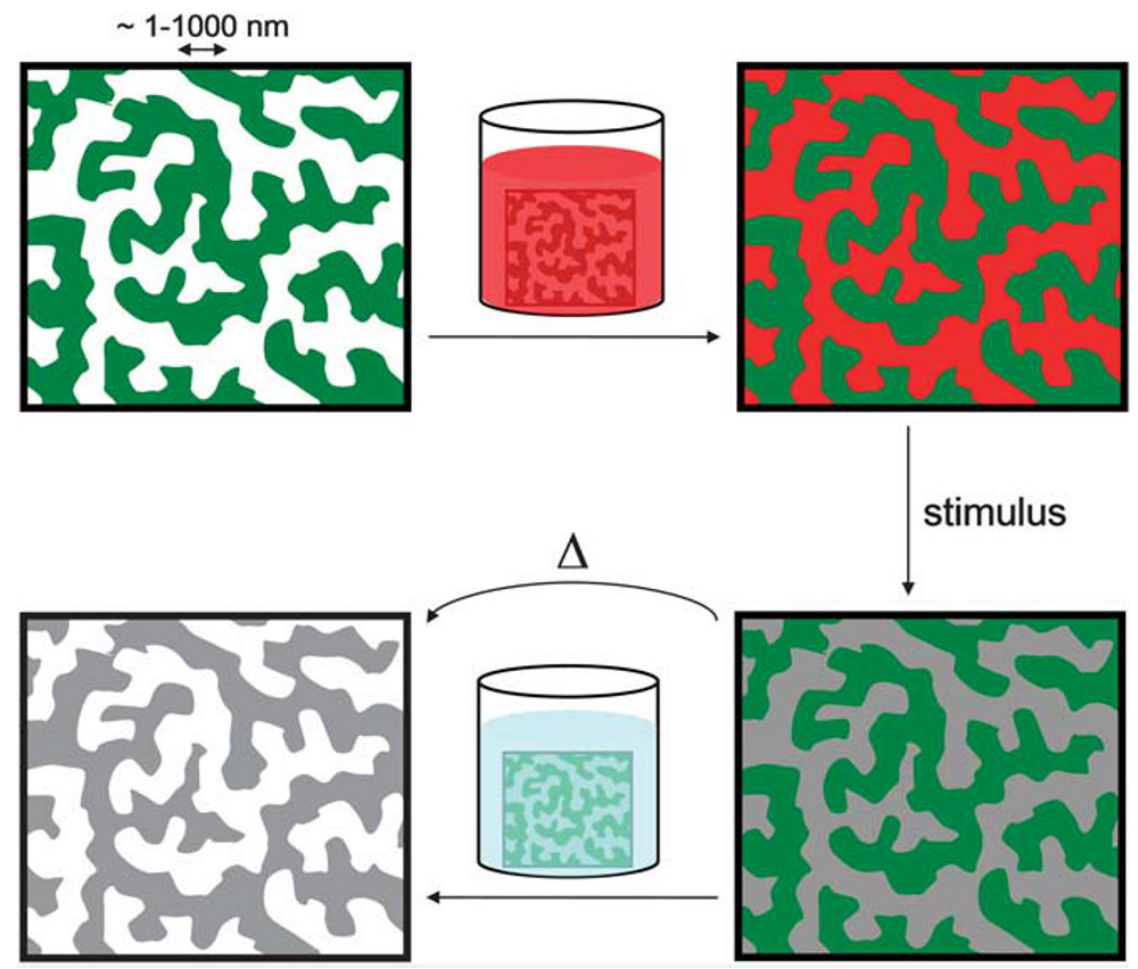

Figure 1 Schematic representation of the general nanocasting process. A nanoporous template (green) is infiltrated with a liquid precursor (red). After infiltration, the precursor is converted to a product (gray) through an external stimulus. Pores are generated in the product by thermal degradation of the template or exposure to a selective chemical agent (turquoise). Adapted with permission from Jones and Lodge. ${ }^{6}$ Copyright 2010 American Chemical Society.

means by which the precursor is transformed to the product. Maximum connectivity is obtained when there are no byproducts from the latter; syntheses conducted in dilute solution are typically challenging to apply. In situations where the entire infiltrated volume of precursor is converted to product, that is, there are no solvents or byproducts, density changes can, nevertheless, still hinder perfect structural replication of the template.

Nanocasting is a complementary synthesis technique-it is dependent on the availability of materials with well-defined nanostructures, produced by alternative techniques. A variety of chemistries have been successfully employed as templates, including surfactant-structured sol-gel materials, ${ }^{8-56}$ block polymer-derived nanoporous materials ${ }^{57-63}$ and colloidal materials. ${ }^{64-84}$ The nanocasting approach summarized here is based on polymeric bicontinuous microemulsions $(\mathrm{B} \mu \mathrm{Es})$. This choice provides a pathway complementary to the various synthetic strategies noted above, and enables the production of bicontinuous materials with highly tailorable chemistry and uniformly shaped, ca. $100 \mathrm{~nm}$ pores. In this review, we will summarize our recent application of the $\mathrm{B} \mu \mathrm{E}$ template to the production of nanoporous polymers, ceramics and hierarchically structured materials. $\mathrm{A} \mathrm{B} \mu \mathrm{E}$ is found under very specific conditions in fluid mixtures containing immiscible substances and a compatibilizing agent. ${ }^{85,86}$ The morphology consists of independent networks of the immiscible substances, which are both three-dimensionally continuous and contain extensive interfacial area and near-zero mean interfacial curvature. These interfaces are not correlated over long length scales, that is, the structure is disordered; however, they exhibit local periodicity on the order of tens of $\mathrm{nm}$ to hundreds of $\mathrm{nm}$. The compatibilizing agent resides primarily at the interface.
$\mathrm{B} \mu \mathrm{Es}$ are not unique to polymeric systems; they were first discovered in mixtures of oil and water stabilized by surfactants. ${ }^{87}$ Bodet et al. ${ }^{88}$ as well as Jahn and Strey, ${ }^{89}$ provided direct proof of the existence of $\mathrm{B} \mu \mathrm{Es}$ in oil-water-surfactant systems using freeze fracture electron microscopy. Teubner and $S$ trey ${ }^{90}$ provided a robust means to quantitatively characterize the inherent periodicity of a microemulsion by using scattering experiments. The intensity, $I$, of electromagnetic radiation scattered by a microemulsion exhibits a broad maximum as a function of scattering angle, or wave vector $q$, following the form:

$$
I \sim \frac{1}{a_{2}+c_{1} q^{2}+c_{2} q^{4}}
$$

where $a_{2}, c_{1}$ and $c_{2}$ are coefficients of a Landau expansion of the free energy density of the system. In particular, $c_{1}<0$ for microemulsions, reflecting the negative interfacial tension characteristic of such fluids. From this description of the scattering, two characteristic length scales arise-the domain spacing $d$ and the correlation length $\xi$ :

$$
\begin{aligned}
& d=2 \pi\left[\frac{1}{2}\left(\frac{a_{2}}{c_{2}}\right)^{1 / 2}-\frac{1}{4} \frac{c_{1}}{c_{2}}\right]^{-1 / 2} \\
& \xi=\left[\frac{1}{2}\left(\frac{a_{2}}{c_{2}}\right)^{1 / 2}+\frac{1}{4} \frac{c_{1}}{c_{2}}\right]^{-1 / 2}
\end{aligned}
$$

The value of $d$ corresponds to the average separation between adjacent identical domains; in other words, $d$ is equal to the sum of the average widths of the water and oil domains. $\xi$ corresponds to the length over which interfaces are correlated; larger values of $\xi$ imply a fluid with a longer range of ordering. 
Ternary polymer blends of two immiscible homopolymers A and $\mathrm{B}$ and the corresponding A-B diblock copolymer constitute highmolecular-weight analogs of oil-water-surfactant mixtures. In such blends, the diblock copolymer prefers to segregate at the interface between $\mathrm{A}$ and $\mathrm{B}$, thereby lowering the interfacial tension. ${ }^{91}$ Since the $\mathrm{B} \mu \mathrm{E}$ morphology occurs in oil-water-surfactant mixtures possessing comparable amounts of oil and water and a small-to-moderate fraction of surfactant, an equivalent morphology could be reasonably expected in polymeric mixtures with comparable amounts of A and B and a small-to-moderate fraction of A-B. Moreover, the chemical equivalence of the homopolymers and the corresponding blocks of the copolymer produces a temperature-independent copolymer solubility, which tends to widen the temperature range over which a $\mathrm{B} \mu \mathrm{E}$ is stable.

Initial studies regarding ternary blends of this nature were primarily theoretical. ${ }^{92-95}$ The anticipated isopleth $\left(\phi_{\mathrm{A}}=\phi_{\mathrm{B}}, f_{\mathrm{A}} \approx 0.5\right.$ and $N_{\mathrm{A}}=N_{\mathrm{B}}$, where $\phi, f$ and $N$ denote volume fraction, volumetric copolymer composition and volumetric degree of polymerization, respectively) phase diagram is reproduced schematically in Figure $2 .{ }^{93}$

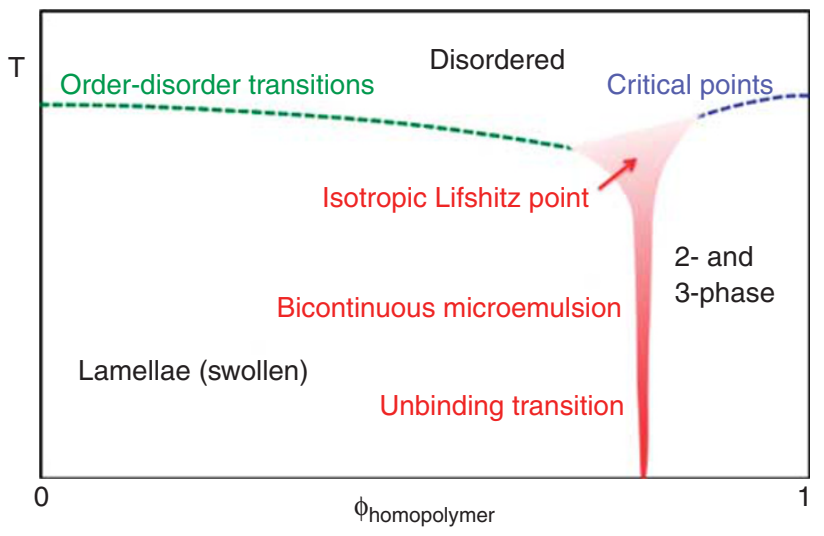

Figure 2 Isopleth phase diagram for symmetric $A / B / A-B$ blends, in which $N_{\mathrm{A}}=N_{\mathrm{B}} \approx 0.2 N_{\mathrm{A}-\mathrm{B}}, \quad \phi_{\mathrm{A}}=\phi_{\mathrm{B}}$ and $f_{\mathrm{A}}=0.5$. Mean-field theory anticipates a Lifshitz point where the line of order-disorder transitions meets the line of critical points, and an unbinding transition separating lamellae from regions of phase separation. Experimentally, both of these features are masked by a channel of bicontinuous microemulsion, shown in red.
At high temperature, $\mathrm{A}$ and $\mathrm{B}$ are miscible and the predicted equilibrium state is a single-phase, homogeneous melt over the entire composition range. At low temperature and high copolymer content, the blend is dominated by the micro-phase separation of the copolymer into alternating lamellae of A and B. As equal amounts of A and B homopolymer are progressively added, the lamellae swell until their spacing diverges. Further increases in homopolymer content result in coexisting A-rich and B-rich phases, as there is insufficient copolymer to suppress macroscopic phase separation. The microemulsion regime intervenes between the lamellar and multi-phase states in oil-watersurfactant mixtures. Interestingly, mean-field theory does not predict the existence of a $\mathrm{B} \mu \mathrm{E}$ in polymeric blends; rather, the transition between lamellae and macro-phase separation occurs directly at an unbinding transition. ${ }^{96}$ This unbinding transition intersects the line defining the phase transitions between the high-temperature, homogeneous and low-temperature, micro- or macro-phase-separated states at an isotropic Lifshitz point. ${ }^{97}$ Broseta and Fredrickson calculated that the Lifshitz point occurs when:

$$
\begin{aligned}
& \phi_{H}=\frac{1}{1+2 \alpha^{2}} \\
& \chi N_{\mathrm{A}-\mathrm{B}}=2 \frac{1+2 \alpha^{2}}{\alpha}
\end{aligned}
$$

where $\phi_{\mathrm{H}}$ is the volume fraction of homopolymers $\left(\phi_{\mathrm{H}}=\phi_{\mathrm{A}}+\phi_{\mathrm{B}}=1-\phi_{\mathrm{A}-\mathrm{B}}\right), \alpha$ is the ratio of homopolymer size to copolymer size $\left(\alpha=N_{\mathrm{H}} / N_{\mathrm{A}-\mathrm{B}}<1\right)$ and $\chi$ is the segment-segment interaction parameter. ${ }^{98}$ In the context of free energy density, a Lifshitz point corresponds to $a_{2}=c_{1}=0$, which, according to equation (2), implies that $I \sim q^{-4}$. For a nearly symmetric blend of polyethylene (PE), poly(ethylene-alt-propylene) (PEP) and poly(ethylene- $b$-ethylene-alt-propylene) (PE-PEP), this scattering behavior was experimentally confirmed at the composition predicted by equation (3). ${ }^{93}$

Bates et al. ${ }^{86}$ first demonstrated the existence of B $\mu$ Es in PE/PEP/ PE-PEP blends using a combination of rheology, scattering and microscopy. Their experimentally determined isopleth phase diagram for this system is reproduced in Figure 3a. The disordered, lamellar and two-phase regions predicted by mean-field theory are reproduced; however, the unbinding transition is preempted by a narrow channel of $\mathrm{B} \mu \mathrm{E}$. A theoretical study of $\mathrm{A} / \mathrm{B} / \mathrm{A}-\mathrm{B}$ blends using fluctuation theory, that was published in the same year as this seminal work,
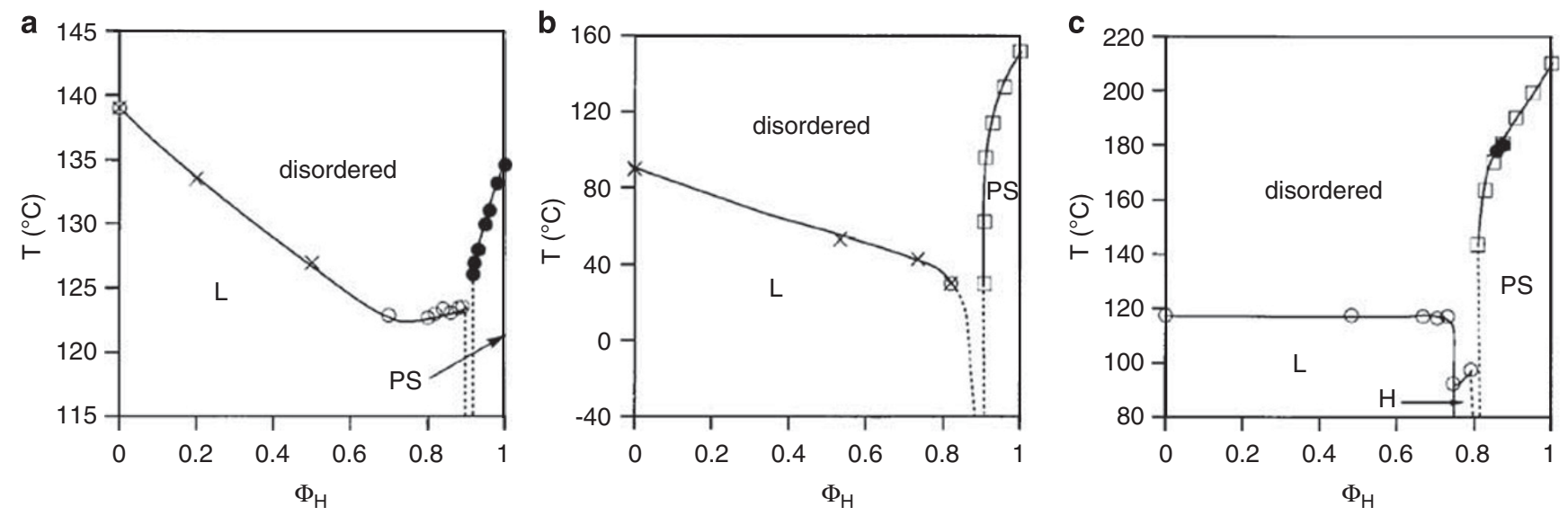

Figure 3 Isopleth phase diagrams for (a) polyethylene/poly(ethylene-alt-propylene)/poly(ethylene-b-ethylene-alt-propylene), (b) poly(ethylethylene)/ poly(dimethylsiloxane)/poly(ethylethylene- $b$-dimethylsiloxane) and (c) polyethylene/poly(ethylene oxide)/poly(ethylene- $b$-ethylene oxide). L, H and PS indicate lamellae, a hexagonally symmetric single phase and macroscopic phase separation, respectively. The phase transitions were determined by rheology $(x)$, small-angle neutron scattering (SANS) $(\bullet, O)$ and cloud point measurements $(\square)$. The dashed lines demarcate the channel over which a bicontinuous microemulsion is stable. Reprinted with permission from Hillmyer et al. ${ }^{101}$ Copyright 1999 American Chemical Society. 
indicated that the Lifshitz point is destroyed. ${ }^{99}$ Nevertheless, the composition and temperature of the Lifshitz point predicted by mean-field theory can be used as a guide to locate the phase space over which a $\mathrm{B} \mu \mathrm{E}$ exists. ${ }^{100}$ Before the unbinding transition is reached, that is, before the lamellar spacing diverges, composition fluctuations destroy the swollen, destabilized lamellae, creating a thermodynamically stable, bicontinuous structure.

Later experimental work demonstrated that the general phase behavior depicted in Figure 3a is universal for symmetric, A/B/A-B, polymeric systems. ${ }^{101}$ Symmetric blends of poly(ethylethylene) (PEE), poly(dimethylsiloxane) (PDMS) and poly(ethylethylene- $b$-dimethylsiloxane) (PEE-PDMS), and PE, poly(ethylene oxide) (PEO) and poly(ethylene- $b$-ethylene oxide) (PE-PEO) were investigated, as well as the PE/PEP/PE-PEP system. In addition, a value of $\alpha \approx 0.2$ was maintained, in an attempt to match the phase-transition temperatures at the composition extremes of the isopleth phase diagram, for experimental convenience. Mean-field theory predicts the order-disorder transition of a symmetric diblock copolymer $\left(\phi_{\mathrm{H}}=0\right)$ and the critical point of a symmetric, binary homopolymer blend $\left(\phi_{\mathrm{H}}=1\right)$ to occur at $\chi N_{\mathrm{A}-\mathrm{B}}=10.5$ and $\chi N_{\mathrm{H}}=2$, respectively, resulting in $\chi N_{\mathrm{H}} /$ $\chi N_{\mathrm{A}-\mathrm{B}}=\alpha \approx 0.2$ (if one assumes a single $\chi$ applies to both copolymers and homopolymers). ${ }^{102}$ Across these systems, the copolymer molecular weights ranged from $108.3 \mathrm{~kg} \mathrm{~mol}^{-1}$ for PE-PEP to $12.7 \mathrm{~kg} \mathrm{~mol}^{-1}$ for PEE-PDMS to $2.13 \mathrm{~kg} \mathrm{~mol}^{-1}$ for PE-PEO. Figure 3, which depicts the phase diagrams from this work, clearly shows the consistency in phase behavior across these systems. A channel of $\mathrm{B} \mu \mathrm{E}$ was observed in all three cases. Also evident from these phase diagrams is the fact that the $\mathrm{B} \mu \mathrm{E}$ channel can exist despite a substantial mismatch ${ }^{102}$ between the phase transition temperatures at the composition extremes of the diagram. Collectively, these results establish that $\mathrm{B} \mu \mathrm{Es}$ can be found in $\mathrm{A} / \mathrm{B} / \mathrm{A}-\mathrm{B}$ polymeric systems of arbitrary chemistry, provided the aforementioned symmetry constraints are appropriately satisfied.

The significant volume of published research conducted toward understanding ternary polymer blends and polymeric $\mathrm{B} \mu \mathrm{Es}$ has laid the foundation for their use as efficient precursors to nanoporous materials. The capture of a polymeric $\mathrm{B} \mu \mathrm{E}$ in a solid form is straightforward in principle, provided the $\mathrm{B} \mu \mathrm{E}$ channel intersects a solidification transition of one of the blend components, such as a glass transition or crystallization point. Through a judicious selection of blend components, one of the three-dimensionally continuous networks comprising a polymeric $\mathrm{B} \mu \mathrm{E}$ can then be voided by selective chemical or thermal means. Zhou et al. ${ }^{103,104}$ reported the only previous example of a porous material derived from a polymeric $\mathrm{B} \mu \mathrm{E}$. The $\mathrm{B} \mu \mathrm{E}$ in a polystyrene (PS)/polyisoprene (PI)/poly(styrene- $b$ isoprene) (PS-PI) blend was first trapped by vitrification of the PS domains. The resultant material was exposed to the vapor of $\mathrm{S}_{2} \mathrm{Cl}_{2}$ to crosslink the PI and, finally, the PS homopolymer was removed by extraction with hexane. Scanning electron microscopy (SEM) images of a fracture surface of the final, monolithic product are shown in Figure 4. The distinctive $\mathrm{B} \mu \mathrm{E}$ structure is retained and imprinted into the pore structure that results from removal of the PS homopolymer. From Figure 4, the pores appear to be uniform in size and interconnected in three dimensions. Indeed, the pores were filled with an ionic liquid and the high ionic conductivity measured of the resulting composite proved the continuity of the pore system across the monolith. In addition, the pore-size distribution calculated from nitrogen sorption measurements exhibited a single peak centered at a pore diameter of $43 \mathrm{~nm}$. The value of $d$ calculated for the starting $\mathrm{B} \mu \mathrm{E}$ from small-angle X-ray scattering data was $80 \mathrm{~nm}$, slightly less than twice the average pore diameter. These results were consistent with the expected structure of a porous material generated by solvation of homopolymer; the copolymer is insoluble in the extracting solvent and, therefore, the PS block of the copolymer remained as a coating along the pore walls.

In the remainder of this review, the $\mathrm{B} \mu \mathrm{E}$-forming polymer system that has been used as a nanocasting template comprises the original $\mathrm{PE} / \mathrm{PEP} / \mathrm{PE}-\mathrm{PEP}$ system. The choice of this system was motivated by several factors. First, the polymers can be synthesized by a straightforward anionic polymerization/hydrogenation procedure ${ }^{105,106}$ and are stable indefinitely under ambient conditions. In addition, the semicrystalline nature of $\mathrm{PE}$ allows the $\mathrm{B} \mu \mathrm{E}$ morphology to be captured in a solid material. ${ }^{107}$ Meanwhile, to convert a solidified $\mathrm{B} \mu \mathrm{E}$ into a nanoporous material, the disparity in solubility between PE and PEP can be exploited to remove the latter from the structure. ${ }^{108}$ The remaining $\mathrm{PE}$ comprising the nanoporous material melts above $\sim 100^{\circ} \mathrm{C}$ and is insoluble in any liquid below $70^{\circ} \mathrm{C}$, thus imparting sufficient robustness to the material for infiltration and conversion of nanocasting precursors in the pores. However, the PE can be dissolved
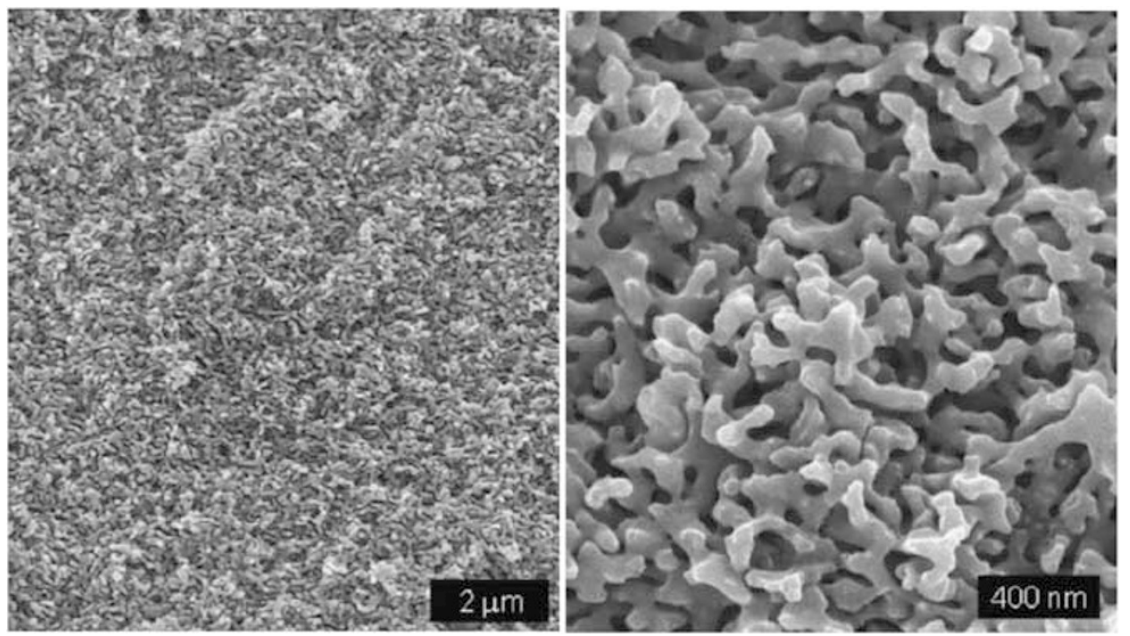

Figure 4 Scanning electron microscopy images of the fracture surface of nanoporous, crosslinked PI monolith derived from a polystyrene/polyisoprene/ poly(styrene- $b$-isoprene) bicontinuous microemulsion. The left and right images are low- and high-magnification views, respectively. Reprinted with permission from Zhou et al. ${ }^{103}$ Copyright 2006 American Chemical Society. 
in a range of solvents at moderate temperature and can be thermally degraded above $500{ }^{\circ} \mathrm{C}$ and, hence, can be readily removed as a nanocasting template.

\section{EXPERIMENTAL PROCEDURE}

\section{Polymer synthesis and characterization}

The synthetic route used to prepare the PE-PEP diblock copolymer is shown in Scheme 1; analogous routes were used to prepare the PE and PEP homopolymers. As a precursor to PE, PEP and PE-PEP, anionic polymerization was used to prepare 1,4-polybutadiene ( $\mathrm{PB}), 1,4$-PI and poly(1,4-butadiene- $b$-1,4-isoprene) (PB-PI), respectively. 1,3-Butadiene (Aldrich, St Louis, MO, USA, $99+\%$ ) was purified by two successive vacuum distillations into evacuated flasks containing dried $n$-butyl lithium (Aldrich, supplied as a $2.5-\mathrm{M}$ solution in hexanes), with stirring for at least $30 \mathrm{~min}$ at $0{ }^{\circ} \mathrm{C}$. 1,3-Isoprene (Aldrich, 99\%) was deoxygenated by three successive freeze-pump-thaw cycles and then further purified by a procedure identical to that used to purify 1,3-butadiene. After purification, both monomers were vacuum-distilled into evacuated, flame-dried burettes and stored at $-78^{\circ} \mathrm{C}$. Sec-butyl lithium (Aldrich, supplied as a 1.4-M solution in cyclohexane) was used as received. Methanol (Mallinckrodt, St Louis, MO, USA, 99.8\%) was deoxygenated by at least three successive freeze-pumpthaw cycles. Typically, between 10 and $50 \mathrm{~g}$ of monomer and 0.5 and 11 of solvent were used. The reaction was terminated by the addition of excess methanol via an argon-purged, gas-tight syringe. The resulting solution was precipitated in a 3:1 methanol:isopropanol mixture and allowed to settle. The supernatant was decanted and the polymer was dried successively under a nitrogen stream and vacuum. The polydienes were stored in air at $-23^{\circ} \mathrm{C}$

\section{Catalytic hydrogenation/deuteration}

To convert the polydiene precursors $\mathrm{PB}$, PI and $\mathrm{PB}-\mathrm{PI}$ to the corresponding polyolefins-PE, PEP and PE-PEP, respectively-unsaturation was removed by a catalyzed reaction with $\mathrm{H}_{2}$ or $\mathrm{D}_{2}$. The polydiene was dissolved in $500 \mathrm{ml}$ of cyclohexane (VWR, 99\%). The polymer solution was added to a thick-walled, 11 stainless-steel reactor, along with the catalyst and a stir bar. The heterogeneous catalyst consisted of platinum and rhenium supported on silica (Dow Chemical, Midland, MI, USA) and was added at $20 \%$ of the polymer weight. The reactor was purged with argon for $20 \mathrm{~min}$ under stirring and then sealed. After sealing, the reactor was pressurized with approximately $500 \mathrm{psi}$ of $\mathrm{H}_{2}$ (Airgas, Radnor, PA, USA, ultra-high purity grade) or $\mathrm{D}_{2}$ (Cambridge Isotope Laboratories, Andover, MA, USA, 99.8\%) and the temperature was raised to $170^{\circ} \mathrm{C}$ and held for $12 \mathrm{~h}$. The PI homopolymer and PB-PI copolymer were reacted with $\mathrm{H}_{2}$ to give fully hydrogenous PEP and PE-PEP, respectively, whereas different samples of the $\mathrm{PB}$ homopolymer were reacted with $\mathrm{H}_{2}$ or $\mathrm{D}_{2}$ to give fully hydrogenous $\mathrm{PE}$ or partially deuterated $\mathrm{PE}$, respectively. Partially deuterated $\mathrm{PE}$ was necessary to provide neutron scattering contrast in $\mathrm{PE} / \mathrm{PEP} /$ PE-PEP blends for the determination of phase behavior by small-angle neutron scattering. After the 12-h reaction time, the reactor was cooled to room temperature for PEP and to $70^{\circ} \mathrm{C}$ for PE and PE-PEP. The solution was then filtered at that temperature to remove the catalyst.

\section{Size exclusion chromatography}

Size exclusion chromatography measurements were performed in tetrahydrofuran (THF) with Phenomenex (Torrance, CA, USA) Phenogel columns packed with porous beads of $5 \times 10^{3}, 5 \times 10^{4}$ and $5 \times 10^{5} \AA$ pore sizes. Solutions were prepared at concentrations ranging from 1 to $7 \mathrm{mg} \mathrm{ml}^{-1}$. The flow rate was controlled at $1 \mathrm{ml} \mathrm{min}^{-1}$ via an Alltech (Deerfield, IL, USA) 426 HPLC positive displacement pump. The eluate was analyzed successively by a Wyatt Technology (Santa Barbara, CA, USA) Dawn DSP multi-angle laser photometer with a 633-nm helium-neon laser and a Wyatt Technology Optilab DSP interferometric refractometer. The molecular weights of PE, PEP and PEPEP were calculated from the molecular weights of PB, PI and PB-PI, respectively, by accounting for the known quantity of additional hydrogen or deuterium. The PE, PEP and PE-PEP were determined to have number-average molecular weights $\left(M_{\mathrm{n}}\right)$ of 23.0 (based on a fully hydrogenated repeat unit), 22.5 and $101 \mathrm{~kg} \mathrm{~mol}^{-1}$ and polydispersity indices of $1.05,1.02$ and 1.07 , respectively.

\section{Nuclear magnetic resonance spectroscopy}

Proton nuclear magnetic resonance spectroscopy was used to determine stereochemistry, copolymer composition and hydrogenation efficiency. The diene precursors and PEP were dissolved in deuterated chloroform at concentrations ranging from $1 \%$ to $5 \%$ by weight, and spectra were acquired using a Varian (Palo Alto, CA, USA) UNITY $300 \mathrm{MHz}$ spectrometer at room temperature. For PE and PE-PEP, spectra were acquired using a Varian INOVA $300 \mathrm{MHz}$ spectrometer at $80^{\circ} \mathrm{C}$ with deuterated toluene as a solvent. Typically, 128 scans were performed and delay and acquisition times of 20 and $3 \mathrm{~s}$ were employed, respectively. The PE homopolymer and PE block of PE-PEP contain 85\% and $87 \%$ linear ethylene units, respectively, while the PEP homopolymer and PEP block of PE-PEP contain $96 \%$ and $95 \%$ ethylene-alt-propylene units, respectively. The PE-PEP contains 50\% PE by volume. Finally, the PE, PEP and PEPEP were determined to be $100 \%$ saturated, within experimental resolution.

\section{Preparation of nanoporous $\mathrm{PE}$}

Blends of PE, PEP and PE-PEP were prepared by dissolving specific volumes of the three polymers in benzene at $70^{\circ} \mathrm{C}$ and then freeze-drying to remove the benzene. Through a combination of rheological measurements, small-angle neutron scattering and transmission electron microscopy (TEM), the isopleth for this system was mapped and the phase space over which a $\mathrm{B} \mu \mathrm{E}$ is stabilized was determined. ${ }^{109}$ Nanoporous PE monoliths were derived from $\mathrm{B} \mu \mathrm{E}$-forming blends by first heating in ampules, typically to $\sim 130^{\circ} \mathrm{C}$, and holding for $2 \mathrm{~h}$. Next, they were immersed in liquid nitrogen to rapidly quench the sample below the crystallization temperature, $T_{\mathrm{c}}$, of PE. A rapid quench is necessary to restrict the crystallization of $\mathrm{PE}$ within the domain structure of the $\mathrm{B} \mu \mathrm{E} \cdot{ }^{107,110}$ Slower rates of cooling lead to large-scale crystallization, which significantly disrupts or destroys the melt structure. The solidified monoliths were recovered from the ampules and pores were created by soaking in THF at room temperature for at least $3 \mathrm{~h}$. The THF was always replenished once during the soaking process. Since PEP is soluble in THF, whereas PE and PE-PEP are

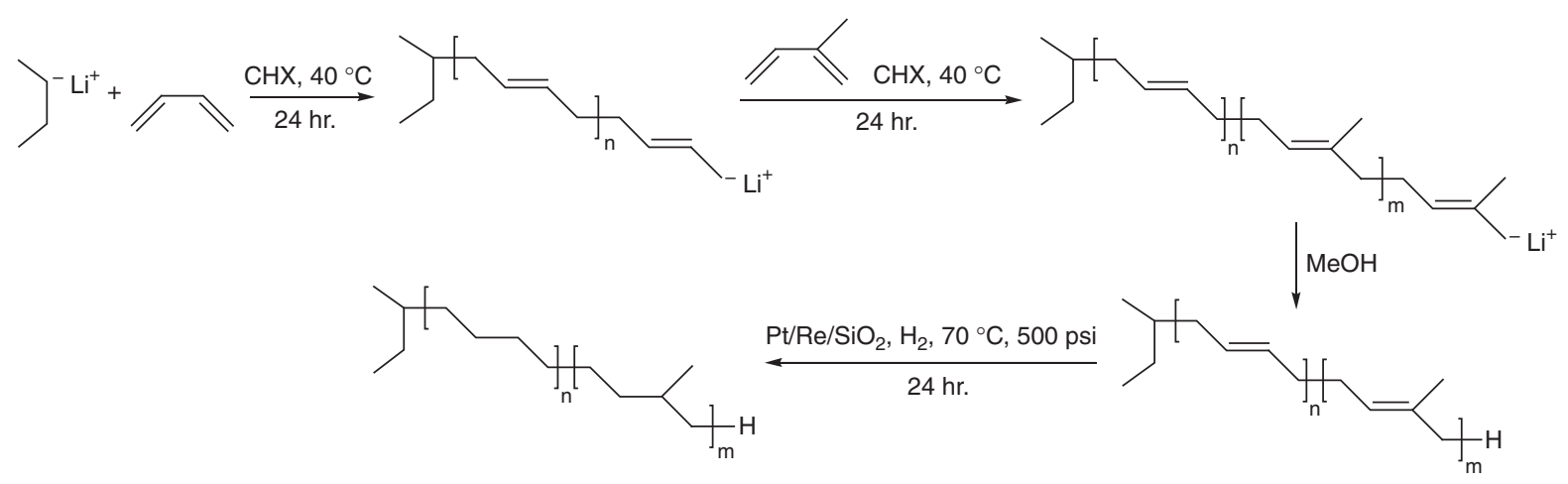

Scheme 1 Synthetic procedure for preparation of poly(ethylene-b-ethylene-alt-propylene) diblock copolymer by anionic polymerization of poly(1,4-butadiene$b$-1,4-isoprene), followed by catalytic hydrogenation. 
not, the PEP homopolymer was removed from the monoliths. After soaking, the nanoporous PE monoliths were dried under vacuum.

\section{Scanning electron microscopy}

A Hitachi (Tokyo, Japan) S-900 microscope was used at operating voltages ranging from 2 to $5 \mathrm{kV}$. For nanoporous $\mathrm{PE}$, very small rectangular bars $(\sim 1 \mathrm{~mm} \times 1 \mathrm{~mm} \times$ several $\mathrm{mm})$ were cut from the monoliths with a razor blade. These bars were then submersed in liquid nitrogen and fractured. The fracture surfaces were mounted on metal stubs via a conductive carbon tape and coated with $\sim 2 \mathrm{~nm}$ of Pt using a VCR indirect ion-beam sputtering system. A typical fracture surface of the nanoporous PE used throughout this work as a nanocasting template is shown in Figure 5. The three-dimensionally continuous pore structure provided by the $\mathrm{B} \mu \mathrm{E}$ from which the material is derived is plainly evident. Similar procedures were used in the SEM analysis of nanoporous monoliths generated by nanocasting with nanoporous $\mathrm{PE}$ as template.

\section{Transmission electron microscopy}

A FEI (Hillsboro, OR, USA) Tecnai $\mathrm{G}^{2} \mathrm{~F} 30$ field emission gun instrument was used, operated at $300 \mathrm{kV}$ accelerating voltage. Images were obtained with a Gatan (Pleasanton, CA, USA) Ultrascan $4000 \times 4000$ pixel charge-coupled device camera. Samples were cut into $\sim 85-200-\mathrm{nm}$ sections at -150 to $-80^{\circ} \mathrm{C}$ using a Leica (Wetzlar, Germany) UC6 cryogenic ultramicrotome. These sections were then dispersed onto an uncoated copper mesh grid.

\section{Porosity measurements}

The porosities of monoliths were probed by two different methods-nitrogen sorption and differential scanning calorimetry (DSC) thermoporometry. Nitrogen sorption is the most commonly employed means to characterize the porosity of nanoporous solids. The technique exploits the fact that a gas confined within a pore condenses at a pressure less than its bulk saturation pressure. ${ }^{111}$ The measurements were conducted at $77 \mathrm{~K}$ using a Quantachrome Instruments (Boynton Beach, FL, USA) Autosorb-1 or Autosorb iQ. The measured samples comprised monoliths that had been broken into several pieces. Pore-size distributions were calculated from the desorption branch of the measured isotherms using the method of Barrett, Joyner and Halenda. ${ }^{112}$ DSC thermoporometry is a much less frequently used technique that, similar to nitrogen sorption, exploits the fact that a liquid confined within a pore freezes-or, equivalently, a solid confined within a pore melts—at a lower temperature than the bulk freezing point of the substance. Brun et al. ${ }^{113}$ were the first to use calorimetry to monitor this depression in freezing point of a confined liquid and its correlation with pore size. As detailed in an extensive review by Landry, ${ }^{114}$ a typical experiment involves the hermetic encapsulation of a small amount of the porous solid of interest combined with a volume of wetting liquid greater than the pore volume of the solid. At present, cyclohexane was used as the probe liquid. Measurements were conducted using a TA Instruments (New Castle, DE, USA) Q1000 DSC. The sample was first rapidly cooled well below the freezing temperature of cyclohexane $\left(6^{\circ} \mathrm{C}\right)$ and then warmed at $0.1{ }^{\circ} \mathrm{Cmin}^{-1}$ from 2 to $7^{\circ} \mathrm{C}$. The obtained DSC traces were converted to pore-size distributions using the procedure of Landry ${ }^{114}$ with appropriate modifications. ${ }^{6}$

\section{RESULTS}

\section{Nanoporous thermosetting polymers}

Thermosets are rigid, highly crosslinked, polymeric materials, synthesized by the condensation polymerization of multi-functional monomers or the chain polymerization of monomers containing multiple vinyl groups. Epoxy resins are typically formed by the reaction of molecules with epoxy and amine functionalities; polyurethanes are formed by the reaction of molecules with isocyanate and alcohol functionalities. Owing to the highly crosslinked structure, thermosets have among the highest moduli, strengths, and thermal and chemical stabilities of any polymeric materials. For several advanced applications, there is the need for easily processable, porous solids possessing such adventitious properties. Porous epoxies, polyurethanes and similar materials have been proposed for use in separations, ${ }^{115}$ encapsulation and electrical insulation of components in microelectronics, ${ }^{116-118}$ battery separators ${ }^{119}$ and stimuli-responsive textiles. ${ }^{120}$

As a first example of the utility of $\mathrm{B} \mu \mathrm{E}$-derived, nanoporous $\mathrm{PE}$ as a nanocasting template, we have generated nanoporous epoxy and polyurethane monoliths. ${ }^{6}$ In the former case, glycidyl end-capped poly(bisphenol A-co-epichlorohydrin) (Aldrich, $M_{\mathrm{n}} \sim 348 \mathrm{~g} \mathrm{~mol}^{-1}$ ) and 4,4'-methylenedianiline (Aldrich) were used as monomers, mixed in a stoichiometric molar ratio of 2:1 poly(bisphenol A-coepichlorohydrin):4,4'-methylenedianiline (see Scheme 2 ). To facilitate uptake by the PE template, the monomers were first dissolved in chloroform or THF at $\sim 50 \%$ by weight. Then, PE monoliths were added to the solution and allowed to rest for at least $1 \mathrm{~h}$. The solvent was removed successively under $\mathrm{N}_{2}$ and vacuum over the course of 2 days. After removing the monoliths and cleaning excess monomer from the surface, the weight increase was consistent with filled pores. The filled monoliths were heated to $90^{\circ} \mathrm{C}$ in air overnight to complete the reaction of the monomers. Subsequent heating to $150{ }^{\circ} \mathrm{C}$ for several hours caused no visual or dimensional change in the monolith, despite the fact that this temperature is well above the melting

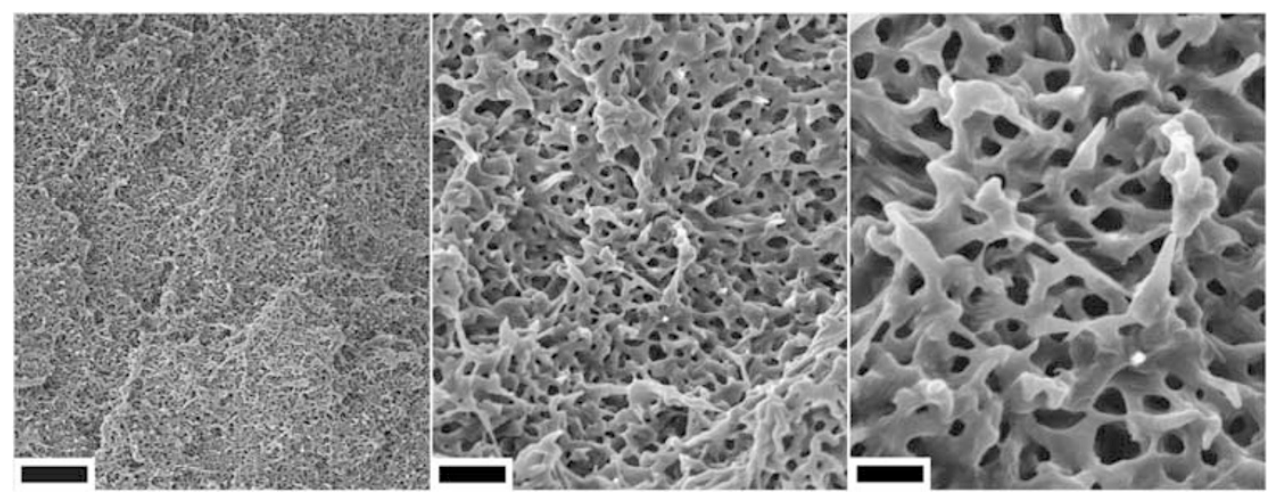

Figure 5 Scanning electron microscopy images of a typical bicontinuous microemulsion-derived, nanoporous polyethylene (PE) monolith used as a nanocasting template throughout this work. This particular monolith was created by annealing a PE/poly(ethylene-alt-propylene) (PEP)/poly(ethylene- $b$ ethylene-alt-propylene) blend with $\phi_{\mathrm{H}}=0.85$ at $127^{\circ} \mathrm{C}$ for $2 \mathrm{~h}$, quenching in liquid nitrogen and removing PEP homopolymer by solvation in tetrahydrofuran. The images were taken after fracturing the monolith while submerged in liquid nitrogen. The right two images are a higher-magnification view of the central portion of the region shown in the corresponding image to the left. The scale bars, from left to right, correspond to $3 \mu \mathrm{m}, 750 \mathrm{~nm}$ and $300 \mathrm{~nm}$, respectively. 
temperature of $\mathrm{PE}$. This indicates the successful crosslinking of the epoxy within the PE pores. The final nanoporous epoxy was generated by soaking the monoliths in toluene at $70^{\circ} \mathrm{C}$ overnight to dissolve $\mathrm{PE}$, followed by removal of the toluene under vacuum.

For the nanoporous polyurethane, toluene diisocyanate (Aldrich) and glycerol propoxylate (Aldrich, $M_{\mathrm{n}} \sim 266 \mathrm{~g} \mathrm{~mol}^{-1}$ ) were used as monomers, mixed in the stoichiometric molar ratio of 3:2 toluene diisocyanate:glycerol propoxylate (Scheme 2). The monomers were directly mixed and stirred until homogeneous. Nanoporous PE monoliths were then added and allowed to rest for $\sim 2 \mathrm{~h}$. This time roughly coincides with the gel time of the mixture; the PE monoliths were simply removed from the mixture just before the gel point was reached. After cleaning the excess monomer, the weights of the monoliths were consistent with the filled pores. Unlike the epoxy case, the PE pores are readily filled without adding a co-solvent. The reaction of the monomers was again completed by heating to $90{ }^{\circ} \mathrm{C}$ in air overnight. The final nanoporous polyurethane was generated by soaking the monoliths in toluene at $70{ }^{\circ} \mathrm{C}$ overnight to dissolve $\mathrm{PE}$, followed by removal of the toluene under vacuum.

Both systems provided excellent nanoporous monoliths, as documented by the SEM images of fracture surfaces of epoxy and polyurethane in Figures 6 and 7, respectively. The images clearly show that the $\mathrm{B} \mu \mathrm{E}$ structure is templated into the pore structure of these materials, resulting in disordered, three-dimensionally continuous pore networks. The epoxy and polyurethane monomers were chosen to yield very tightly crosslinked networks, that is, a low average molecular weight between crosslinks. This choice was intended to minimize the swelling of the networks by toluene during dissolution of the PE template and,<smiles>CCOc1ccc(C(C)(C)c2ccc(OCC(O)COc3ccc(C(C)(C)c4ccc(OCC5CO5)cc4)cc3)cc2)cc1OCC1CO1</smiles>

Scheme 2 Chemical structures of monomers glycidyl end-capped poly(bisphenol A-co-epichlorohydrin) (top left), 4,4'-methylenedianiline (bottom left), toluene-2,4-diisocyanate (center) and glycerol propoxylate (right). The particular grade of toluene diisocyanate used is an 80:20 mixture of 2,4:2,6 isomers.

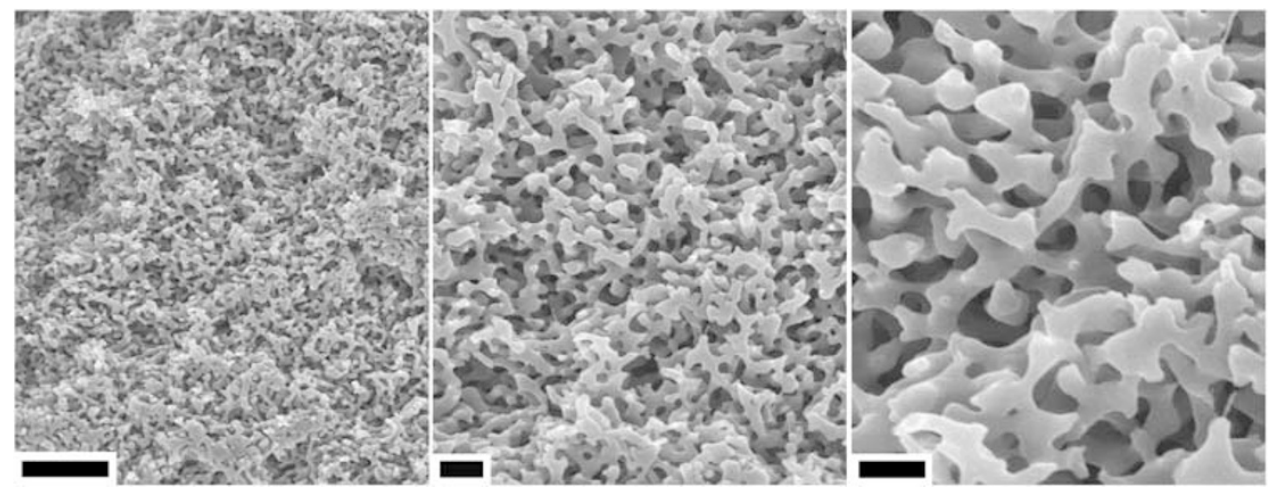

Figure 6 Scanning electron microscopy images of a fracture surface of nanoporous epoxy monolith at different magnifications. The scale bars, from left to right, correspond to $2 \mu \mathrm{m}, 500 \mathrm{~nm}$ and $300 \mathrm{~nm}$, respectively.

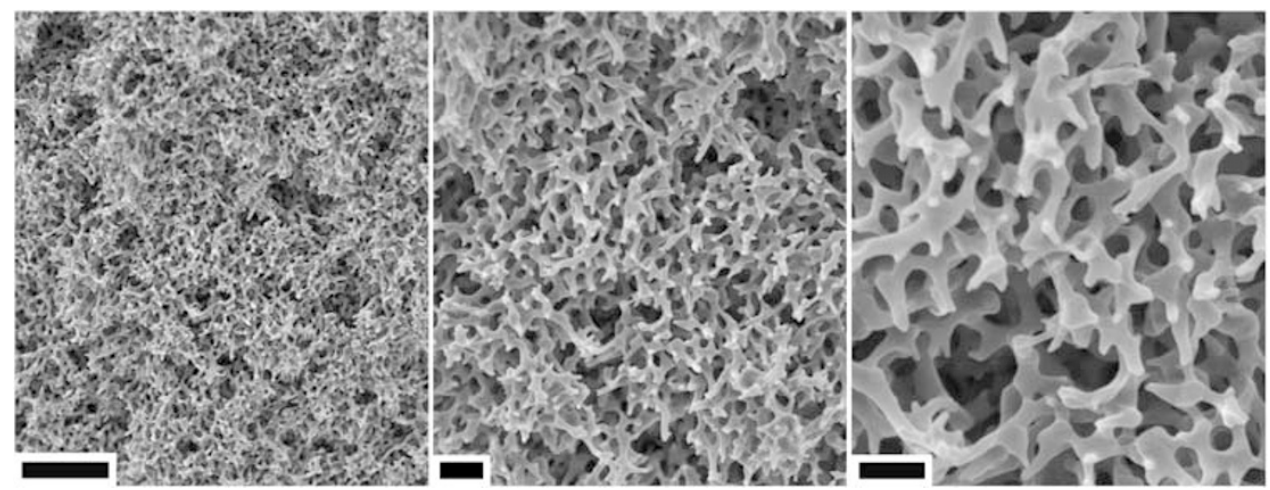

Figure 7 Scanning electron microscopy images of a fracture surface of nanoporous polyurethane monolith at different magnifications. The scale bars, from left to right, correspond to $2 \mu \mathrm{m}, 500 \mathrm{~nm}$ and $300 \mathrm{~nm}$, respectively. 
thus, avoid a decrease in the modulus of the networks such that porosity could no longer be supported. Presumably, if the molecular weight of the poly(bisphenol A-co-epichlorohydrin) or glycerol propoxylate monomers was progressively increased, at some critical value the nanocasting procedure would cease to reproduce the $\mathrm{B} \mu \mathrm{E}$ structure in these porous materials. This underscores a limitation of the nanocasting procedure used, namely that the synthesized product must be sufficiently intractable or have otherwise limited interaction with a good solvent for PE. DSC thermoporometry measurements indicated that both materials possess uniform pore-size distributions centered at $\sim 100 \mathrm{~nm}$, consistent with the domain spacing of the original $\mathrm{B} \mu \mathrm{E}$ from which the monoliths are derived, ${ }^{6}$ as described in more detail later. Furthermore, internal surface areas of $\sim 30-35 \mathrm{~m}^{2} \mathrm{~g}^{-1}$ were measured.

\section{Nanoporous poly(3,4-ethylenedioxythiophene) (PEDOT)}

PEDOT is an important, commercially available conducting polymer and its synthesis, properties and applications have been studied extensively. ${ }^{121,122}$ PEDOT possesses excellent chemical and thermal stability, unique electrochemical and spectroscopic properties, and inherently high conductivity. Consequently, it has been suggested for use in a wide range of applications, including antistatic coatings, capacitors, thin-film transistors, and electroluminescent and photovoltaic devices. ${ }^{123-130}$ Owing to the demand for porous materials with good stability, high conductivity and large internal surface area in sensor, battery, capacitor and storage technologies, ${ }^{131}$ it is desirable to develop PEDOT materials possessing controlled porosity. To this end, a high-surface-area PEDOT electrode has been demonstrated as an effective $\mathrm{O}_{2}$ reduction catalyst in fuel cells and batteries, ${ }^{132}$ and macroporous PEDOT films have been used as counter-electrodes in dye-sensitized solar cells. ${ }^{133}$

We have demonstrated nanoporous PE as a template by which nanoporous PEDOT monoliths are conveniently nanocast. ${ }^{134}$ EDOT monomer can be polymerized electrochemically or by initiation with a suitable oxidant, ${ }^{135}$ such as the salts iron(III) chloride ${ }^{135}$ and iron(III) tris- $p$-toluenesulfonate ${ }^{136}\left(\mathrm{Fe}(\mathrm{OTs})_{3}\right)$. Oxidation of PEDOT chains leaves the final product in a doped, conducting state. PEDOT synthesized by this method is insoluble, but can be processed into transparent films with conductivities approaching $1000 \mathrm{~S} \mathrm{~cm}^{-1} .^{137}$ The synthetic route to PEDOT employed in our work was the chemical oxidative polymerization of EDOT (Aldrich) initiated by $\mathrm{Fe}(\mathrm{OTs})_{3}$ (Aldrich). The polymerization is extremely rapid and is typically conducted in solution. ${ }^{136}$ To adapt this polymerization to the present nanocasting method, several experimental challenges had to be solved. The solution-based synthesis of PEDOT within the pores of a nanoporous PE monolith is not a viable means to template the structure of the latter, because the majority component-the solvent-is removed after polymerization. Ideally, $\mathrm{Fe}(\mathrm{OTs})_{3}$ would be directly dissolved in the liquid EDOT monomer and the mixture then infiltrated into nanoporous $\mathrm{PE}$ and allowed to react. This is impossible, however, due to the extremely rapid kinetics of polymerization and the high loadings of $\mathrm{Fe}(\mathrm{OTs})_{3}$ required for sufficient doping of the final PEDOT. ${ }^{137}$ Therefore, nanoporous PE monoliths were first impregnated with pure EDOT monomer. A solution of $72 \mathrm{wt} \% \mathrm{Fe}(\mathrm{OTs})_{3}$ in isopropanol, with an absolute amount of $\mathrm{Fe}(\mathrm{OTs})_{3}$ corresponding to a $\mathrm{Fe}(\mathrm{OTs})_{3}$ : EDOT molar ratio of 2:1, was prepared at $80^{\circ} \mathrm{C}$. While at $80^{\circ} \mathrm{C}$, the EDOT-filled monoliths were exposed to this solution. After a few hours, the resulting black monoliths were removed, washed with excess isopropanol and dried under vacuum. The final nanoporous PEDOT was generated by soaking the monoliths in toluene at $70^{\circ} \mathrm{C}$ overnight to dissolve $\mathrm{PE}$, followed by vacuum removal of the toluene.

In Figure 8, SEM images of a fracture surface of a typical nanoporous PEDOT monolith are presented. The PEDOT is quite sensitive to beam damage in the microscope, of which the thin fiberlike objects seen at higher magnification are a direct result. Nevertheless, the images clearly show that the $\mathrm{B} \mu \mathrm{E}$ structure is templated into the pore structure of the PEDOT, resulting in a disordered, threedimensionally continuous pore network. This result further demonstrates that the nanocasting procedure can be successfully applied when the desired product is not a crosslinked network, but rather is simply insoluble in a good solvent for PE. Nitrogen sorption measurements indicated a relatively uniform pore-size distribution centered roughly at $100-200 \mathrm{~nm} .{ }^{134}$ The internal surface area of the material calculated by the method of Brunauer, Emmett and Teller ${ }^{138}$ was $26 \mathrm{~m}^{2} / \mathrm{g}$. Both of these values are comparable to those of the nanoporous thermosets, highlighting the consistency with which the nanocasting technique replicates the initial $\mathrm{B} \mu \mathrm{E}$ structure.

\section{Amorphous ceramics}

As a third example of the utility of $\mathrm{B} \mu \mathrm{E}$-derived, nanoporous $\mathrm{PE}$ as a nanocasting template, we have generated nanoporous, high-temperature, ceramic monoliths. ${ }^{6,139}$ In the synthesis of nanoporous silicon carbonitride, a commercially available polysilazane, Ceraset 20 (KiON Specialty Polymers, Huntingdon Valley, PA, USA), was used as a precursor. Polysilazanes possess low glass-transition temperatures, ${ }^{140}$ and thus Ceraset 20 is a liquid at room temperature. Its general chemical structure ${ }^{141}$ is shown in Scheme 3. Blends of Ceraset 20 and $1 \mathrm{wt} \%$ dicumyl peroxide (Acros Organics, Geel, Belgium) were pre-

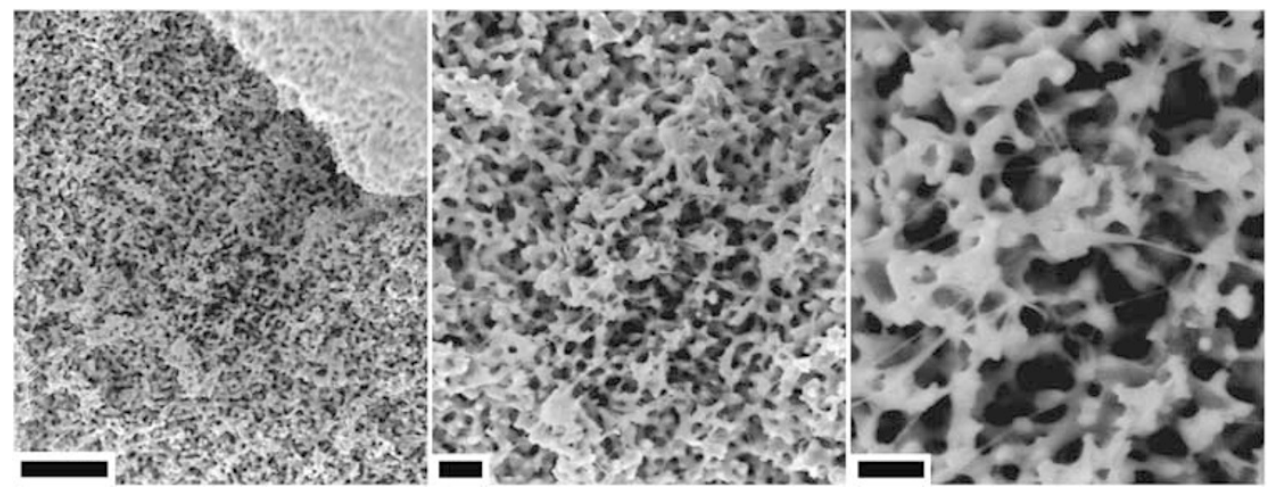

Figure 8 Scanning electron microscopy images of a fracture surface of nanoporous PEDOT monolith at different magnifications. The scale bars, from left to right, correspond to $2 \mu \mathrm{m}, 500 \mathrm{~nm}$ and $300 \mathrm{~nm}$, respectively. 
pared by direct dissolution. The nanoporous PE monoliths were added to the Ceraset/peroxide blends so as to infiltrate and fill the $\mathrm{PE}$ pores. After allowing the nanoporous $\mathrm{PE}$ monoliths to rest in the Ceraset/peroxide blends overnight, the monoliths were removed and excess blend was cleaned from the surface. Gravimetry confirmed that the pores had spontaneously filled with precursor. The monoliths were heated to $90^{\circ} \mathrm{C}$ for $48 \mathrm{~h}$ to crosslink the Ceraset via reaction of peroxide fragments with the vinyl substituents of the polysilazane. Finally, the composite monoliths of PE and crosslinked Ceraset were converted to the final nanoporous ceramic product by heating under flowing $\mathrm{N}_{2}$ to $1000{ }^{\circ} \mathrm{C}$ at a rate of $2{ }^{\circ} \mathrm{C} \mathrm{min}{ }^{-1}$. The monoliths were held at $1000^{\circ} \mathrm{C}$ for $2 \mathrm{~h}$ and then cooled to room temperature at the rate of $2{ }^{\circ} \mathrm{Cmin}^{-1}$. It is important to note that all steps of this synthesis procedure were conducted in air, with the exception of the aforementioned pyrolysis step.

SEM images of a fracture surface of a typical nanoporous silicon carbonitride monolith are shown in Figure 9. Once again, the $\mathrm{B} \mu \mathrm{E}$ structure has been templated into the pore structure of the nanocast material. To confirm that the pores in this material result from complete degradation of the PE template during the pyrolysis and conversion of the Ceraset precursor to silicon carbonitride, a sample of PE was subjected to thermogravimetric analysis. This analysis indicated that $\mathrm{PE}$ is completely degraded above $\sim 500{ }^{\circ} \mathrm{C}$ when heated in $\mathrm{N}_{2}$. The Ceraset-ceramic conversion is accompanied by an overtwofold isotropic increase in the density of the material. A comparison of the SEM images in Figure 9 indicates a decrease in both the pore size and pore wall size of the ceramic, relative to the PE template (Figure 5), which is undoubtedly a consequence of this shrinkage. It is remarkable that the $\mathrm{B} \mu \mathrm{E}$ structure and monolith integrity are so wellpreserved after synthesis, considering the drastic physical changes that are incurred. Presumably, the slow temperature ramp rate employed during pyrolysis is crucial in this regard, so as to avoid prohibitive accumulation of thermal stress. The present nanoporous ceramic exhibited excellent thermal stability when heated in air to $1000^{\circ} \mathrm{C}$, as indicated by zero weight loss during thermogravimetric analysis, as

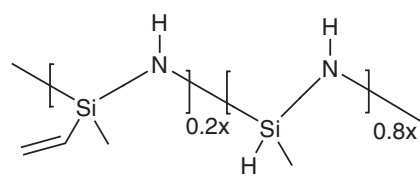

Scheme 3 Chemical structure of Ceraset 20 polysilazane used as a precursor in the synthesis of SiCN ceramic. well as by subsequent SEM analysis, whereby an identical pore structure was observed.

To characterize the pore-size distribution of the nanoporous ceramic quantitatively, both nitrogen sorption and DSC thermoporometry were used. The pore-size distributions obtained from both techniques are simultaneously displayed in Figure 10. The data in both cases show a relatively narrow distribution in pore sizes centered at $\sim 80 \mathrm{~nm}$. The domain spacing of the starting $\mathrm{B} \mu \mathrm{E}$ is $c a .160 \mathrm{~nm}$. To a first approximation, the pore size of the ceramic should correspond to the sum of the size of the PE domains and the size of the PEP block of the PE-PEP block copolymer, as these are the components of the starting ternary polymer blend that comprise the nanoporous PE template. The ternary blend consists of 57.5 vol.\% PE homopolymer and PEPEP block copolymer, so the expected pore size by this approximation is $160 \mathrm{~nm} \times 0.575$, or $92 \mathrm{~nm}$. Of course, it is reasonable to expect the actual pore size to be less than this estimate, given the previously discussed density change of the ceramic during synthesis. Therefore, this estimated pore size is in good agreement with the experimental value. In Figure 10, the upper and lower accessible pore sizes by nitrogen sorption and DSC thermoporometry are also apparent.

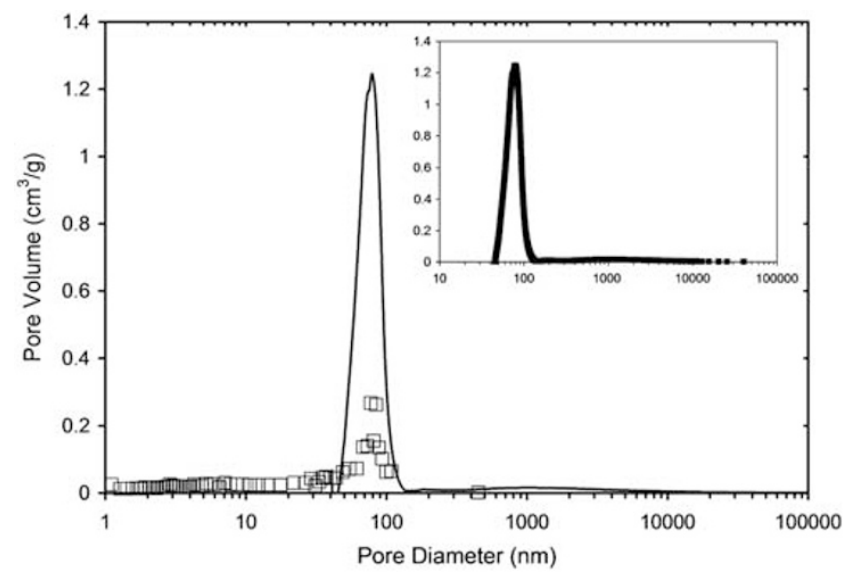

Figure 10 Pore-size distribution of nanoporous ceramic determined by nitrogen sorption (open symbols) and differential scanning calorimetry (DSC) thermoporometry (solid line). The latter data are plotted as a solid line owing to the high density of data points and to highlight the dearth of nitrogen sorption data at pore sizes $>100 \mathrm{~nm}$. The inset shows the DSC thermoporometry data plotted as individual data points.

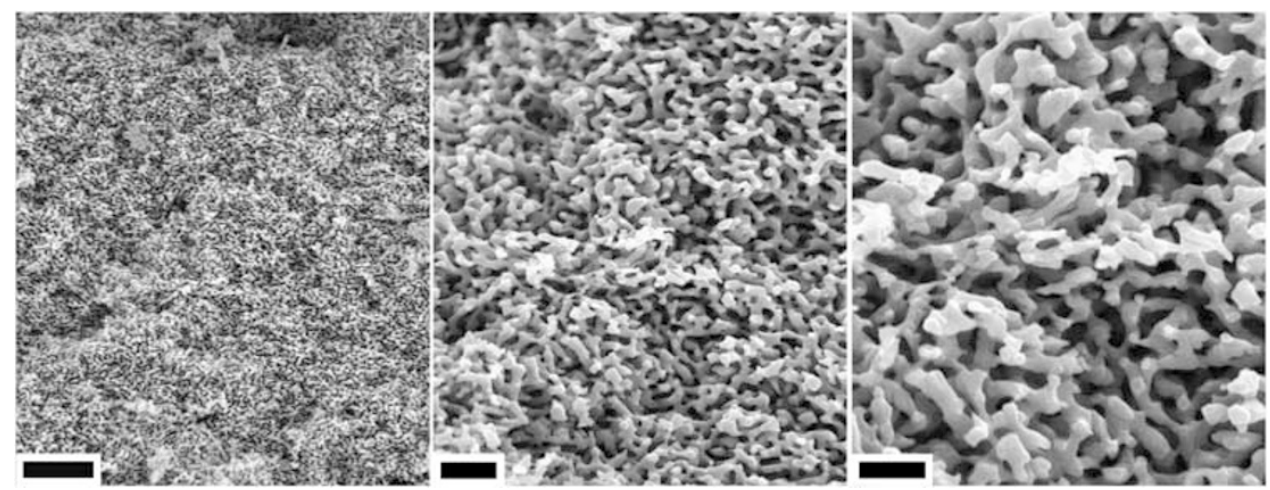

Figure 9 Scanning electron microscopy images of a fracture surface of nanoporous silicon carbonitride monolith at different magnifications. The scale bars, from left to right, correspond to $2 \mu \mathrm{m}, 500 \mathrm{~nm}$ and $300 \mathrm{~nm}$, respectively. 
Nitrogen sorption indicates negligible pore volume in the ceramic from pores with sizes covering the range of $1-50 \mathrm{~nm}$, but is insensitive to pores with sizes $>100 \mathrm{~nm}$. Conversely, DSC thermoporometry indicates negligible pore volume from pores with sizes covering the range of approximately $200 \mathrm{~nm}$ up to $10 \mu \mathrm{m}$, but provides essentially no information on pores with sizes $<40 \mathrm{~nm}$.

\section{Hierarchically structured materials}

There is widespread interest in preparing self-assembled materials with two or more characteristic length scales. ${ }^{142-203}$ As described herein, nanocasting provides simple pathways to such hierarchically structured materials by the self-assembly of multi-phase precursors within rigid templates. In 2004, Zhou et al. ${ }^{204}$ described a new synthetic route to mesostructured $\mathrm{SiO}_{2}$ monoliths through the condensation of tetramethylorthosilicate with the ionic liquid 1-butyl-3-methylimidazolium tetrafluoroborate- $[\mathrm{BMIM}]\left[\mathrm{BF}_{4}\right]$-as a solvent. After gelation, the ionic liquid was selectively extracted. The resulting $\mathrm{SiO}_{2}$ material contained a bicontinuous, disordered network of wormlike mesopores with uniform pore sizes of $\sim 2.5 \mathrm{~nm}$ and a periodicity of $\sim 5 \mathrm{~nm}$, that is, pore wall thicknesses of $\sim 2.5 \mathrm{~nm}$. We have adapted this unique route to mesostructured $\mathrm{SiO}_{2}$ to our nanocasting strategy, thereby enabling the production of hierarchically structured $\mathrm{SiO}_{2} \cdot{ }^{205}$ The choice of ionic liquid as a solvent is critical, as its non-volatility and active role in the mesoscale templating of the condensing $\mathrm{SiO}_{2}$ network enable successful nanocasting. Comparable volumes of $[\mathrm{BMIM}]\left[\mathrm{BF}_{4}\right]$ and tetramethylorthosilicate were mixed and infiltrated into nanoporous $\mathrm{PE}$ monoliths, after which the mixture was exposed to an acid catalyst to initiate the sol-gel reaction of tetramethylorthosilicate. TEM images of the hierarchically structured material obtained after the completion of gelation are shown in Figure 11. From these images, two distinct, periodic arrangements of matter are apparent. First, a comparatively large-scale, disordered, bicontinuous structure is observed, consisting of interpenetrating networks of untextured and textured phases. This arrangement corresponds to the $\mathrm{B} \mu \mathrm{E}$ structure provided by the nanoporous template, with the untextured and textured phases demarcating the PE and the infiltrated gel, respectively. Indeed, the periodicity of this arrangement is on the order of $\sim 100-200 \mathrm{~nm}$, consistent with the domain spacing of the starting $\mathrm{B} \mu \mathrm{E}$. Second, a comparatively small-scale, disordered, bicontinuous structure is observed, confined within the textured phase and consisting of interpenetrating networks of bright and dark phases. This arrangement corresponds to the expected mesoscale structure of the infiltrated gel, with the bright and dark phases demarcating the [BMIM] $\left[\mathrm{BF}_{4}\right]$ and $\mathrm{SiO}_{2}$, respectively. Overall, these TEM images show that the nanocasting strategy enables the straightforward production of hierarchical, tricontinuous, polymer-ceramic-ionic liquid composite monoliths having two characteristic length scales.

Two independent pore networks can be rendered in the material shown in Figure 11 through sequential voiding of the $\mathrm{PE}$ and [BMIM] $\left[\mathrm{BF}_{4}\right]$ domains with selective solvents. Subsequent SEM and TEM analysis (not shown) revealed a hierarchically porous material with a structure identical to that shown in Figure 11, except that the $\mathrm{PE}$ and $[\mathrm{BMIM}]\left[\mathrm{BF}_{4}\right]$ domains were, as expected, converted to threedimensionally continuous $\sim 100$ and $\sim 6 \mathrm{~nm}$ pore networks, respectively. A more quantitative description of the pore characteristics of this hierarchically porous $\mathrm{SiO}_{2}$ was provided by nitrogen sorption measurements, as shown in Figure 12. The isotherm exhibits two distinct steps along both the adsorption and desorption branches, with the typical hysteresis that accompanies capillary condensation and evaporation. This is a direct reflection of the hierarchical arrangement

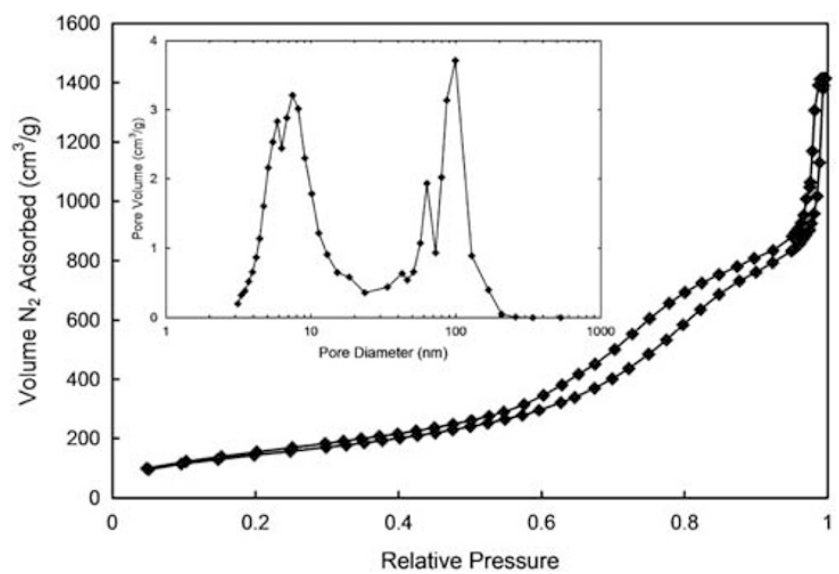

Figure 12 Nitrogen adsorption/desorption isotherm of hierarchically porous $\mathrm{SiO}_{2}$ obtained by nanocasting of mesostructured $\mathrm{SiO}_{2}$ with nanoporous PE as a template. The inset shows the pore-size distribution of the material calculated from the desorption branch of the isotherm using the method of Barrett, Joyner and Halenda. ${ }^{112}$ Reprinted with permission from Jones and Lodge. ${ }^{205}$ Copyright 2011 American Chemical Society.
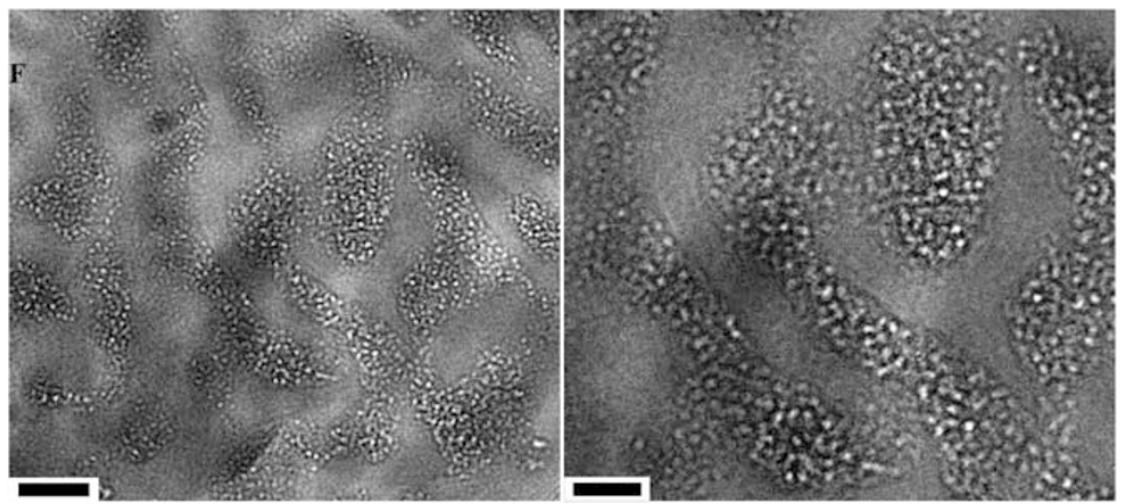

Figure 11 Transmission electron microscopy images of hierarchically structured polyethylene (PE)- $\mathrm{SiO}_{2}-1$-butyl-3-methylimidazolium tetrafluoroborate ([BMIM] $\left[\mathrm{BF}_{4}\right]$ ) monolith obtained by synthesis of mesostructured $\mathrm{SiO}_{2}$ within nanoporous $\mathrm{PE}$. The PE appears as the untextured phase, while the $\mathrm{SiO}_{2}$ and $[\mathrm{BMIM}]\left[\mathrm{BF}_{4}\right]$ appear as the dark and bright components of the textured phase, respectively. Scale bars indicate $100 \mathrm{~nm}$ (left) and $50 \mathrm{~nm}$ (right). Reprinted with permission from Jones and Lodge. ${ }^{205}$ Copyright 2011 American Chemical Society. 
of pores, as the lower and higher relative pressures of the steps can be attributed to the small and large pores generated by the removal of $[\mathrm{BMIM}]\left[\mathrm{BF}_{4}\right]$ and $\mathrm{PE}$, respectively. Indeed, the pore-size distribution shown in the inset of Figure 12 possesses two distinct maxima at pore diameters slightly less than $10 \mathrm{~nm}$ and slightly greater than $100 \mathrm{~nm}$. By comparison with, for example, Figure 10, the larger pores present in the $\mathrm{SiO}_{2}$ material are consistent with the expected size generated by the nanocasting technique. In contrast to the previously mentioned examples, the simultaneous presence of smaller mesopores within the walls of the large pore framework confers exceptionally high internal surface area to the material $\left(570 \mathrm{~m}^{2} \mathrm{~g}^{-1}\right)$, as assessed by the method of Brunauer, Emmett and Teller. We anticipate that this unique hierarchically porous material could be an excellent candidate for applications requiring both high surface area and low mass transport barriers, owing to the highly interconnected nature of the pores.

We have also generated novel hierarchically structured materials that are entirely polymeric through the infiltration and self-assembly of poly(isoprene- $b$-2-vinylpyridine) (PI-P2VP) diblock copolymers within nanoporous PE. ${ }^{206}$ As a model example, a PI-P2VP copolymer having $M_{\mathrm{n}}=41 \mathrm{~kg} \mathrm{~mol}^{-1}$, a narrow molecular-weight distribution and $18 \%$ PI by vol. was used. The equilibrium bulk morphology of the copolymer consists of hexagonally packed cylinders of PI of $13 \mathrm{~nm}$ diameter and $31 \mathrm{~nm}$ spacing, as assessed by small-angle X-ray scattering and TEM. PE monoliths were first allowed to imbibe a concentrated solution of copolymer in THF. With the monoliths submerged, the THF was slowly evaporated over a week or more. This procedure not only induces self-assembly of the PI-P2VP confined by the PE pore network, but also maximizes the copolymer loading within the pores. The resultant composite monoliths of PE and PI-P2VP were then exposed to the vapor of diiodobutane to effect crosslinking of the P2VP component. Separate experiments performed on bulk PI-P2VP confirmed that this procedure does not significantly alter its selfassembled structure.

The PI-P2VP confined and self-assembled within nanoporous PE exhibits a morphology that is markedly different from its bulk counterpart. Representative TEM images of the hierarchically structured PE/PI-P2VP composite are shown in Figure 13. As in the previous case (Figure 11), two distinct, periodic arrangements of matter are observed. The comparatively large-scale, disordered, bicontinuous structure provided by the $\mathrm{B} \mu \mathrm{E}$ template is apparent at low magnification (Figures 13a and b). The bright, untextured and dark, textured networks correspond to the PE and PI-P2VP, respectively. Within the latter, micro-phase separation between PI and P2VP is readily observed at higher magnification (Figures $13 \mathrm{c}$ and $\mathrm{d}$ ). The particular sample shown was stained with $\mathrm{OsO}_{4}$ before imaging; hence, the PI domains appear darker than the diiodobutane-crosslinked P2VP domains. The PI-P2VP exhibits three distinct regions of micro-phase separation as a function of local proximity to the $\mathrm{PE} /$ copolymer interface. First, this interface is wetted exclusively by PI, as indicated by the thin dark layer immediately adjacent to the bright PE domains. This is a consequence of the preference of PI over P2VP to form an interface with polyolefins, which is easily rationalized by considering the relative values of $\chi$ for this system. ${ }^{207,208}$ Second, a much thicker layer, rich in P2VP, occurs adjacent to the PI wetting layer. This P2VP-rich layer is likely enforced by the depletion of PI to the $\mathrm{PE} /$ copolymer interface, coupled with the relatively low volume fraction of PI constituting the copolymer. This phenomenon is similar to reported observations in diblock copolymer thin films that exhibit preferential wetting of one block to a substrate. ${ }^{209}$ Third, along the core of the channels occupied by PI-P2VP, cylinders, discs and helices comprising PI are dispersed in a continuous P2VP matrix. The PI
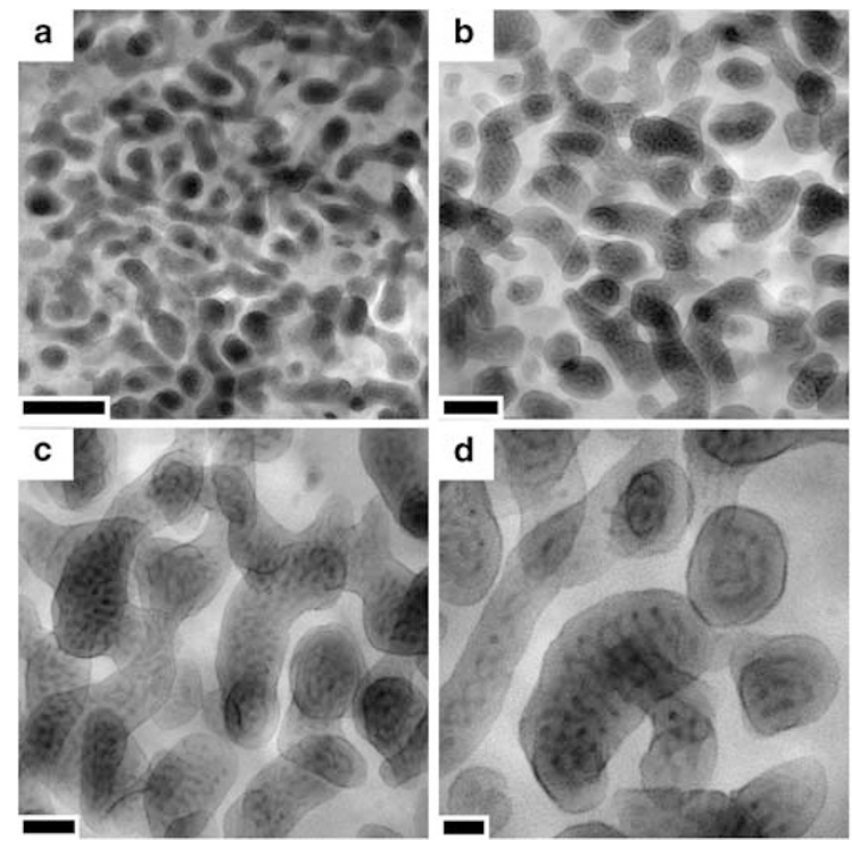

Figure 13 Transmission electron microscopy images of hierarchically structured polyethylene (PE)/poly(isoprene-b-2-vinylpyridine) (PI-P2VP) monolith obtained by confined self-assembly of PI-P2VP within nanoporous $\mathrm{PE}$. The P2VP is crosslinked by diiodobutane and the $\mathrm{PI}$ is stained with $\mathrm{OsO}_{4}$. The relative brightness of the domains follows the order PE $>$ P2VP $>$ PI. Scale bars indicate (a) $400 \mathrm{~nm}$, (b) $200 \mathrm{~nm}$, (c) $100 \mathrm{~nm}$ and (d) $50 \mathrm{~nm}$. Reprinted with permission from Jones and Lodge. ${ }^{206}$ Copyright 2011 American Chemical Society.

objects are clearly aligned parallel to the PE/copolymer interface, that is, the confining pore walls of the PE template. However, it is difficult to resolve the particular connectivity of many of the PI objects, primarily due to the overlapping effect created by the projection of the three-dimensional sample volume into a two-dimensional image.

The self-assembly of diblock copolymers confined within nanoporous materials has, in fact, been recently studied in detail. ${ }^{210}$ The perturbation of morphologies relative to the bulk is indeed a universal feature under strong confinement. A significant portion of the published work has focused on the behavior of bulk-cylinder-forming copolymers within the cylindrical pores of anodic aluminum oxide. ${ }^{62,63,211-222}$ A critical parameter that can be correlated to the observed morphology is the ratio of the confining pore diameter $(D)$ to the bulk copolymer period $\left(L_{0}\right)$. For example, Dobriyal et al. ${ }^{219}$ examined the morphology of PS-PB in anodic aluminum oxide over a $D / L_{0}$ range from 0.92 to 2.22 . With increasing $D / L_{0}$, stacked discs, stacked torus-like structures, single helices, double helices, combinations of rings, cylinders and helices, and triple helices of the minority component were identified. Furthermore, hexagonally packed cylinders of the minority component have been identified at even larger $D /$ $L_{0}$ values. ${ }^{212}$ In all cases, the minority domains were aligned parallel to the long axis of the pores. The morphology of PI-P2VP confined within nanoporous PE described above is consistent with the previous work. Based on the bulk, equilibrium period of PI-P2VP and the pore-size distribution of $\mathrm{PE}$, determined by small-angle X-ray scattering and nitrogen sorption measurements, respectively, the estimated range of $D / L_{0}$ for this system is 1.9-3.2. Therefore, a variety of cylindrical, disc-like and helical PI domains are expected. Moreover, the confining pores, despite being highly tortuous and interconnected, 
are locally cylindrical in shape. Thus, the preference for the PI domains to align parallel to the pore walls is further expected, and is indeed evident from Figure 13. Through the bicontinuous structure of the confining template, self-assembled block copolymer morphologies representative of two-dimensional confinement are obtained in a three-dimensionally continuous manner. More importantly, these results demonstrate that our nanocasting strategy provides a simple pathway to unique, hierarchically structured polymeric materials

\section{DISCUSSION/FUTURE PROSPECTS}

The recent work summarized in this review establishes the following important conclusions. A wide variety of solid materials, including polymeric thermosets, conducting polymers, block copolymers, amorphous ceramics and mesoporous silica, can be readily prepared as nanoporous monoliths, based on a single polymeric $\mathrm{B} \mu \mathrm{E}$ template. The resulting porosities, average pore sizes and pore-size distributions replicate the corresponding features of the template with good fidelity. The initial template is derived from an equilibrium-structured fluid based on a ternary polymer bend, and is thus highly reproducible. The existence of this phase has previously been demonstrated to be universal in appropriately designed systems, thereby indicating that templates could be prepared from a rich variety of starting polymer materials. Given the flexibility in choice of template and in choice of target solid material, there is no obvious limit to the kinds of materials that could be employed. Furthermore, the desirability of nanoporous materials with three-dimensionally connected, ca. $100 \mathrm{~nm}$ pores for multiple applications, ranging from separations and catalysis to batteries and fuel cells, suggests that much further work can be done. Possible future directions to consider include the following:

(i) Surface functionalization of the pores: This could be achieved either by installing appropriately reactive groups in the initial copolymer surfactant or by direct modification of the product surface.

(ii) Tuning of the average pore size: In principle, the domain size of the initial structured fluid is sensitive to blend composition and temperature, and can be tuned over the approximate range $50-250 \mathrm{~nm}$. Whether this tunability can be transferred to the resulting nanoporous product remains to be established.

(iii) Production of new bicontinuous $C / D$ materials: In the work summarized here, an $\mathrm{A} / \mathrm{B}$ template led to a nanoporous $\mathrm{C}$ material. These pores could themselves be filled with the precursor to a new solid, D. A candidate system could include a hole-conducting $\mathrm{C}$ polymer and an electron-conducting D phase, with photovoltaic materials in mind.

\section{ACKNOWLEDGEMENTS}

This work was supported by the National Science Foundation through the University of Minnesota MRSEC, Award DMR-0819885. Graduate School and Doctoral Dissertation Fellowships from the University of Minnesota (BHJ) are gratefully acknowledged. Portions of this work were carried out using instrumentation provided by the University of Minnesota Characterization Facility. We thank Michael Bluemle, Kevin Cavicchi, Kai-Yuan Cheng, Soo-Hyung Choi, Melissa Fierke, Guillaume Fleury, Lorraine Francis, Chris Frethem, Brian Habersberger, Robert Hafner, Russell Holmes, Hau-Nan Lee, Yu Lei, Chun Liu, Ameara Mansour, Lucas McIntosh, Adam Moughton, Andreas Stein, Jared Stoeger, Rajiv Taribagil, Wei Xie and Wei Zhang for their assistance and helpful discussions.
1 Ying, J. Y. Nanostructural tailoring: opportunities for molecular engineering in catalysis. AlChE J. 46, 1902-1906 (2000)

2 Jackson, E. A. \& Hillmyer, M. A. Nanoporous membranes derived from block copolymers: from drug delivery to water filtration. ACS Nano 4, 3548-3553 (2010).

3 Haberkorn, N., Lechmann, M. C., Sohn, B. H., Char, K., Gutmann, J. S. \& Theato, P. Templated organic and hybrid materials for optoelectronic applications. Macromol. Rapid Commun. 30, 1146-1166 (2009).

4 Morris, R. E. \& Wheatley, P. S. Gas storage in nanoporous materials. Angew. Chem. Int. Ed. 47, 4966-4981 (2008).

5 Lu, A.- H., Zhao, D. \& Wan, Y. Nanocasting: A Versatile Strategy for Creating Nanostructured Porous Materials (Royal Society of Chemistry, Cambridge, 2009).

6 Jones, B. H. \& Lodge, T. P. Nanoporous materials derived from polymeric bicontinuous microemulsions. Chem. Mater. 22, 1279-1281 (2010).

7 Washburn, E. W. The dynamics of capillary flow. Phys. Rev. 17, 273-283 (1921).

8 Ryoo, R., Joo, S.- H. \& Jun, S. Synthesis of highly ordered carbon molecular sieves via template-mediated structural transformation. J. Phys. Chem. B 103, 7743-7746 (1999).

9 Lee, J., Yoon, S., Oh, S. M., Shin, C.- H. \& Hyeon, T. Development of a new mesoporous carbon using an HMS aluminosilicate template. Adv. Mater. 12, 359-362 (2000).

10 Jun, S., Joo, S. H., Ryoo, R., Kruk, M., Jaroniec, M., Liu, Z., Ohsuna, T. \& Terasaki, 0. Synthesis of new, nanoporous carbon with hexagonally ordered mesostructure. J. Am. Chem. Soc. 122, 10712-10713 (2000).

11 Kim, S.- S. \& Pinnavaia, T. J. A low cost route to hexagonal mesostructured carbon molecular sieves. Chem. Commun. 2418-2419 (2001).

12 Joo, S. H., Choi, S. J., Oh, I., Kwak, J., Liu, Z., Terasaki, O. \& Ryoo, R. Ordered nanoporous arrays of carbon supporting high dispersions of platinum nanoparticles. Nature 412, 169-172 (2001).

13 Kaneda, M., Tsubakiyama, T., Carlsson, A., Sakamoto, Y., Ohsuna, T., Terasaki, O., Joo, S. H. \& Ryoo, R. Structural study of mesoporous MCM-48 and carbon networks synthesized in the spaces of MCM-48 by electron crystallography. J. Phys. Chem. B $106,1256-1266$ (2002).

14 Che, S., Garcia-Bennett, A. E., Liu, X., Hodgkins, R. P., Wright, P. A., Zhao, D., Terasaki, O. \& Tatsumi, T. Synthesis of large-pore la (3)d mesoporous silica and its tubelike carbon replica. Angew. Chem. Int. Ed. 42, 3930-3934 (2003).

15 Che, S., Lund, K., Tatsumi, T., lijima, S., Joo, S. H., Ryoo, R. \& Terasaki, 0. Direct observation of $3 \mathrm{~d}$ mesoporous structure by scanning electron microscopy (SEM): SBA-15 silica and CMK-5 carbon. Angew. Chem. Int. Ed. 42, 2182-2185 (2003).

16 Yoon, S. B., Kim, J. Y., Yu, J.- S., Gierszal, K. P. \& Jaroniec, M. Fabrication and characterization of mesostructured silica, hum-1, and its ordered mesoporous carbon replica. Ind. Eng. Chem. Res. 44, 4316-4322 (2005).

17 Kim, T.- W., Ryoo, R., Gierszal, K. P., Jaroniec, M., Solovyov, L. A., Sakamoto, Y. \& Terasaki, O. Characterization of mesoporous carbons synthesized with SBA-16 silica template. J. Mater. Chem. 15, 1560-1571 (2005).

18 Kruk, M., Dufour, B., Celer, E. B., Kowalewski, T., Jaroniec, M. \& Matyjaszewski, K. Synthesis of mesoporous carbons using ordered and disordered mesoporous silica templates and polyacrylonitrile as carbon precursor. J. Phys. Chem. B 109, 9216-9225 (2005).

19 Fuertes, A. B. \& Centeno, T. A. Mesoporous carbons with graphitic structures fabricated by using porous silica materials as templates and iron-impregnated polypyrrole as precursor. J. Mater. Chem. 15, 1079-1083 (2005).

20 Li, H., Sakamoto, Y., Li, Y., Terasaki, O., Thommes, M. \& Che, S. Synthesis of carbon replicas of SBA-1 and SBA-7 mesoporous silicas. Micropor. Mesopor. Mater. 95, 193-199 (2006)

21 Kim, T.- W. \& Solovyov, L. A. Synthesis and characterization of large-pore ordered mesoporous carbons using gyroidal silica template. J. Mater. Chem. 16, 1445-1455 (2006).

22 Chang, H., Joo, S. H. \& Pak, C. Synthesis and characterization of mesoporous carbon for fuel cell applications. J. Mater. Chem. 17, 3078-3088 (2007).

23 Sang, L. C., Vinu, A. \& Coppens, M.- O. Ordered mesoporous carbon with tunable, unusually large pore size and well-controlled particle morphology. J. Mater. Chem. 21, 7410-7417 (2011).

24 Ryoo, R., Jun, S., Kim, J. M. \& Kim, M. J. Generalised route to the preparation of mesoporous metallosilicates via post-synthetic metal implantation. Chem. Commun. 2225-2226 (1997)

25 Laha, S. C. \& Ryoo, R. Synthesis of thermally stable mesoporous cerium oxide with nanocrystalline frameworks using mesoporous silica templates. Chem. Commun. 2138-2139 (2003)

26 Rossinyol, E., Arbiol, J., Peiró, F., Cornet, A., Morante, J. R., Tian, B., Bo, T. \& Zhao, D. Nanostructured metal oxides synthesized by hard template method for gas sensing applications. Sensor. Actuat. B 109, 57-63 (2005).

27 Roggenbuck, J., Schäfer, H., Tsoncheva, T., Minchev, C., Hanss, J. \& Tiemann, M. Mesoporous $\mathrm{CeO}_{2}$ : synthesis by nanocasting, characterisation and catalytic properties. Micropor. Mesopor. Mater. 101, 335-341 (2007).

28 Yue, W. \& Zhou, W. Porous crystals of cubic metal oxides templated by cagecontaining mesoporous silica. J. Mater. Chem. 17, 4947-4952 (2007).

29 Tian, B., Liu, X., Solovyov, L. A., Liu, Z., Yang, H., Zhang, Z., Xie, S., Zhang, F., Tu, B., Yu, C., Terasaki, O. \& Zhao, D. Facile synthesis and characterization of novel mesoporous and mesorelief oxides with gyroidal structures. J. Am. Chem. Soc. 126, 865-875 (2004). 
30 Rumplecker, A., Kleitz, F., Salabas, E.- L. \& Schüth, F. Hard templating pathways for the synthesis of nanostructured porous $\mathrm{C}_{3} \mathrm{O}_{4}$. Chem. Mater. 19, 485-496 (2007).

31 Jiao, F., Shaju, K. M. \& Bruce, P. G. Synthesis of nanowire and mesoporous low-temperature $\mathrm{LiCoO}_{2}$ by a post-templating reaction. Angew. Chem. Int. Ed. 44, 6550-6553 (2005).

32 Tüysüz, H., Salabaș, E. L., Weidenthaler, C. \& Schüth, F. Synthesis and magnetic investigation of ordered mesoporous 2-line ferrihydrite. J. Am. Chem. Soc. 130, 280-287 (2008).

33 Dibandjo, P., Bois, L., Chassagneux, F., Cornu, D., Letoffe, J.- M., Toury, B., Babonneau, F. \& Miele, P. Synthesis of boron nitride with ordered mesostructure. Adv. Mater. 17, 571-574 (2005).

34 Dibandjo, P., Chassagneux, F., Bois, L., Sigala, C. \& Miele, P. Comparison between SBA-15 silica and CMK-3 carbon nanocasting for mesoporous boron nitride synthesis. J. Mater. Chem. 15, 1917-1923 (2005).

35 Dibandjo, P., Chassagneux, F., Bois, L., Sigala, C. \& Miele, P. Synthesis of boron nitride with a cubic mesostructure. Micropor. Mesopor. Mater. 92, 286-291 (2006).

36 Shi, Y., Meng, Y., Chen, D., Cheng, S., Chen, P., Yang, H., Wan, Y. \& Zhao, D. Highly ordered mesoporous silicon carbide ceramics with large surface areas and high stability. Adv. Funct. Mater. 16, 561-567 (2006).

37 Yan, J., Wang, A. \& Kim, D.- P. Preparation of ordered mesoporous SiC from preceramic polymer templated by nanoporous silica. J. Phys. Chem. B 110, 5429-5433 (2006)

38 Krawiec, P., Geiger, D. \& Kaskel, S. Ordered mesoporous silicon carbide (OM-SiC) via polymer precursor nanocasting. Chem. Commun. 2469-2470 (2006).

39 Yan, J., Wang, A. \& Kim, D.- P. Preparation of ordered mesoporous SiCN ceramics with large surface area and high thermal stability. Micropor. Mesopor. Mater. 100, 128-133 (2007).

40 Shi, Y., Wan, Y., Zhai, Y., Liu, R., Meng, Y., Tu, B. \& Zhao, D. Ordered mesoporous $\mathrm{SiOC}$ and SiCN ceramics from atmosphere-assisted in situ transformation. Chem. Mater. 19, 1761-1771 (2007).

41 Shi, Y., Wan, Y., Tu, B. \& Zhao, D. Nanocasting synthesis of ordered mesoporous silicon nitrides with a high nitrogen content. J. Phys. Chem. C 112, 112-116 (2008).

42 Han, Y.- J., Kim, J. M. \& Stucky, G. D. Preparation of noble metal nanowires using hexagonal mesoporous silica SBA-15. Chem. Mater. 12, 2068-2069 (2000).

43 Liu, Z., Sakamoto, Y., Ohsuna, T., Hiraga, K., Terasaki, O., Ko, C. H., Shin, H. J. \& Ryoo, R. TEM studies of platinum nanowires fabricated in mesoporous sílica MCM-41. Angew. Chem. Int. Ed. 39, 3107-3110 (2000).

44 Shin, H. J., Ko, C. H. \& Ryoo, R. Synthesis of platinum networks with nanoscopic periodicity using mesoporous silica as template. J. Mater. Chem. 11, 260-261 (2001).

45 Shin, H. J., Ryoo, R., Liu, Z. \& Terasaki, O. Template synthesis of asymmetrically mesostructured platinum networks. J. Am. Chem. Soc. 123, 1246-1247 (2001).

46 Wang, D., Luo, H., Kou, R., Gil, M. P., Xiao, S., Golub, V. O., Yang, Z., Brinker, C. J. \& $\mathrm{Lu}, \mathrm{Y}$. A general route to macroscopic hierarchical 3d nanowire networks. Angew. Chem. Int. Ed. 43, 6169-6173 (2004).

47 Sakamoto, Y., Fukuoka, A., Higuchi, T., Shimomura, N., Inagaki, S. \& Ichikawa, M. Synthesis of platinum nanowires in organic-inorganic mesoporous silica templates by photoreduction: formation mechanism and isolation. J. Phys. Chem. B 108, 853-858 (2004).

48 Fukuoka, A., Higuchi, T., Ohtake, T., Oshio, T., Kimura, J., Sakamoto, Y., Shimomura, N., Inagaki, S. \& Ichikawa, M. Nanonecklaces of platinum and gold with high aspect ratios synthesized in mesoporous organosilica templates by wet hydrogen reduction. Chem. Mater. 18, 337-343 (2006).

49 Urade, V. N., Wei, T.- C., Tate, M. P., Kowalski, J. D. \& Hillhouse, H. W. Nanofabrication of double-gyroid thin films. Chem. Mater. 19, 768-777 (2007).

50 Lee, K.- B., Lee, S.- M. \& Cheon, J. Size-controlled synthesis of Pd nanowires using a mesoporous silica template via chemical vapor infiltration. Adv. Mater. 13, 517-520 (2001).

51 Zhang, Z., Dai, S., Blom, D. A. \& Shen, J. Synthesis of ordered metallic nanowires inside ordered mesoporous material through electroless deposition. Chem. Mater. 14, 965-968 (2002).

52 Wang, D., Zhou, W. L., McCaughy, B. F., Hampsey, J. E., Ji, X., Jiang, Y.- B., Xu, H., Tang, J., Schmehl, R. H., O'Conner, C., Brinker, C. J. \& Lu, Y. Electrodeposition of metallic nanowire thin films using mesoporous silica templates. Adv. Mater. 15, 130-133 (2003).

53 Lee, K., Kim, Y.- H., Han, S. B., Kang, H., Park, S., Seo, W. S., Park, J. T., Kim, B. \& Chang, S. Osmium replica of mesoporous silicate MCM-48: efficient and reusable catalyst for oxidative cleavage and dihydroxylation reactions. J. Am. Chem. Soc. 125, 6844-6845 (2003).

54 Worboys, L. M., Edwards, P. P. \& Anderson, P. A. Silver nanowires: inclusion in and extrusion from a mesoporous template. Chem. Commun. 2894-2895 (2002).

55 Shon, J. K., Kong, S. S., Kim, J. M., Ko, C. H., Jin, M., Lee, Y. Y., Hwang, S. H., Yoon, J. A. \& Kim, J.- N. Facile synthesis of highly ordered mesoporous silver using cubic mesoporous silica template with controlled surface hydrophobicity. Chem. Commun. 650-652 (2009).

56 Kim, J. Y., Yoon, S. B., Kooli, F. \& Yu, J.- S. Synthesis of highly ordered mesoporous polymer networks. J. Mater. Chem. 11, 2912-2914 (2001).

57 Gong, Y., Joo, W., Kim, Y. \& Kim, J. K. Inorganic nanoporous films from block copolymer thin film. Chem. Mater. 20, 1203-1205 (2008).

58 Crossland, E. J. W., Kamperman, M., Nedelcu, M., Ducati, C., Wiesner, U., Smilgies, D.- M., Toombes, G. E. S., Hillmyer, M. A., Ludwigs, S., Steiner, U. \& Snaith, H. J. A bicontinuous double gyroid hybrid solar cell. Nano Lett. 9, 2807-2812 (2009).
59 Hsueh, H.- Y., Chen, H.- Y., She, M.- S., Chen, C.- K., Ho, R.- M., Gwo, S., Hasegawa, H. \& Thomas, E. L. Inorganic gyroid with exceptionally low refractive index from block copolymer templating. Nano Lett. 10, 4994-5000 (2010).

60 Ndoni, S., Li, L., Schulte, L., Szewczykowski, P. P., Hansen, T. W., Guo, F., Berg, R. H. $\&$ Vigild, M. E. Controlled photooxidation of nanoporous polymers. Macromolecules 42, 3877-3880 (2009)

61 Hsueh, H.- Y., Huang, Y.- C., Ho, R.- M., Lai, C.- H., Makida, T. \& Hasegawa, H. Nanoporous gyroid nickel from block copolymer templates via electroless plating. Adv. Mater. 23, 3041-3046 (2011).

62 Wang, Y, Qin, Y., Berger, A., Yau, E., He, C, Zhang, L., Gosele, U., Knez, M. \& Steinhart, M. Nanoscopic morphologies in block copolymer nanorods as templates for atomic-layer deposition of semiconductors. Adv. Mater. 21, 2763-2766 (2009).

63 Chen, D., Park, S., Chen, J.- T., Redston, E. \& Russell, T. P. A simple route for the preparation of mesoporous nanostructures using block copolymers. ACS Nano $\mathbf{3}$, 2827-2833 (2009).

64 Li, Q., Retsch, M., Wang, J., Knoll, W. \& Jonas, U. Porous networks through colloidal templates. Top. Curr. Chem. 287, 135-180 (2009).

65 Wang, Y., Price, A. D. \& Caruso, F. Nanoporous colloids: building blocks for a new generation of structured materials. J. Mater. Chem. 19, 6451-6464 (2009).

66 Velev, O. D., Jede, T. A., Lobo, R. F. \& Lenhoff, A. M. Porous silica via colloidal crystallization. Nature 389, 447-448 (1997).

67 Zakhidov, A. A., Baughman, R. H., Iqbal, Z., Cui, C., Khayrullin, I., Dantas, S. O., Marti, J. \& Ralchenko, V. G. Carbon structures with three-dimensional periodicity at optical wavelengths. Science 282, 897-901 (1998).

68 Holland, B. T., Blanford, C. F. \& Stein, A. Synthesis of macroporous minerals with highly ordered three-dimensional arrays of spheroidal voids. Science $\mathbf{2 8 1}, 538-540$ (1998).

69 Wijnhoven, J. E. G. J \& Vos, W. L. Preparation of photonic crystals made of air spheres in titania. Science 281, 802-804 (1998).

70 Yan, H., Blanford, C. F., Holland, B. T., Parent, M., Smyrl, W. H. \& Stein, A. A chemical synthesis of periodic macroporous $\mathrm{NiO}$ and metallic Ni. Adv. Mater. 11, 1003-1006 (1999).

71 Velev, O. D., Tessier, P. M., Lenhoff, A. M. \& Kaler, E. W. Materials: a class of porous metallic nanostructures. Nature 401, 548 (1999).

72 Jiang, P., Cizeron, J., Bertone, J. F. \& Colvin, V. L. Preparation of macroporous metal films from colloidal crystals. J. Am. Chem. Soc. 121, 7957-7958 (1999).

73 Vlasov, Y. A., Yao, N. \& Norris, D. J. Synthesis of photonic crystals for optical wavelengths from semiconductor quantum dots. Adv. Mater. 11, 165-169 (1999).

74 Park, S. H. \& Xia, Y. Fabrication of three-dimensional macroporous membranes with assemblies of microspheres as templates. Chem. Mater. 10, 1745-1747 (1998)

75 Park, S. H. \& Xia, Y. Macroporous membranes with highly ordered and threedimensionally interconnected spherical pores. Adv. Mater. 10, 1045-1048 (1998).

76 Johnson, S. A., Ollivier, P. J. \& Mallouk, T. E. Ordered mesoporous polymers of tunable pore size from colloidal silica templates. Science 283, 963-965 (1999).

77 Jiang, P., Hwang, K. S., Mittleman, D. M., Bertone, J. F. \& Colvin, V. L. Templatedirected preparation of macroporous polymers with oriented and crystalline arrays of voids. J. Am. Chem. Soc. 121, 11630-11637 (1999).

78 Wang, H., Li, X., Yu, J. \& Kim, D. Fabrication and characterization of ordered macroporous PMS-derived SiC from a sacrificial template method. J. Mater. Chem. 14, 1383-1386 (2004)

79 Meyer, U., Larsson, A., Hentze, H.- P. \& Caruso, R. A. Templating of porous polymeric beads to form porous silica and titania spheres. Adv. Mater. 14, 1768-1772 (2002).

80 Shchukin, D. G. \& Caruso, R. A. Template synthesis of porous gold microspheres. Chem. Commun. 1478-1479 (2003).

81 Shchukin, D. G. \& Caruso, R. A. Template synthesis and photocatalytic properties of porous metal oxide spheres formed by nanoparticle infiltration. Chem. Mater. 16, 2287-2292 (2004)

82 Wang, M.- L., Wang, C.- H. \& Wang, W. Porous macrobeads composed of metal oxide nanocrystallites and with percolated porosity. J. Mater. Chem. 17, 2133-2138 (2007).

83 Sizgek, D. G., Griffith, C. S., Sizgek, E. \& Luca, V. Mesoporous zirconium titanium oxides. Part 3. Synthesis and adsorption properties of unfunctionalized and phosphonate-functionalized hierarchical polyacrylonitrile-F-127-templated beads. Langmuir 25, 11874-11882 (2009).

84 Wang, M.- L., Wang, C.- H. \& Wang, W. Preparation of porous $\mathrm{ZrO}_{2} / \mathrm{Al}_{2} \mathrm{O}_{3}$ macrobeads from ion-exchange resin templates. J. Mater. Sci. 46, 1220-1227 (2011).

85 Scriven, L. E. Equilibrium bicontinuous structure. Nature 263, 123-125 (1976).

86 Bates, F. S., Maurer, W. W., Lipic, P. M., Hillmyer, M. A., Almdal, K., Mortensen, K., Fredrickson, G. H. \& Lodge, T. P. Polymeric bicontinuous microemulsions. Phys. Rev. Lett. 79, 849-852 (1997).

87 Lindman, B., Kamenka, N., Kathopoulis, T.- M., Brun, B. \& Nilsson, P.- G. Translational diffusion and solution structure of micro-emulsions. J. Phys. Chem. 84, 2485-2490 (1980).

88 Bodet, J.- F., Bellare, J. R., Davis, H. T., Scriven, L. E. \& Miller, W. G. Fluid microstructure transition from globular to bicontinuous in midrange microemulsion. J. Phys. Chem. 92, 1898-1902 (1988).

89 Jahn, W. \& Strey, R. Microstructure of microemulsions by freeze-fracture electronmicroscopy. J. Phys. Chem. 92, 2294-2301 (1988).

90 Teubner, M. \& Strey, R. Origin of the scattering peak in microemulsions. J. Chem. Phys. 87, 3195-3200 (1987).

91 Noolandi, J. \& Hong, K. M. Interfacial properties of immiscible homopolymer blends in the presence of block copolymers. Macromolecules 15, 482-492 (1982) 
92 Holyst, R. \& Schick, M. Copolymers as amphiphiles in ternary mixtures: an analysis employing disorder, equimaxima, and Lifshitz lines. J. Chem. Phys. 96, 7728-7737 (1992).

93 Bates, F. S., Maurer, W. W., Lodge, T. P., Schulz, M. F., Matsen, M. W., Almdal, K. \& Mortensen, K. Isotropic Lifshitz behavior in block copolymer-homopolymer blends. Phys. Rev. Lett. 75, 4429-4432 (1995).

94 Janert, P. K. \& Schick, M. Phase behavior of ternary homopolmer/diblock blends: influence of relative chain lengths. Macromolecules 30, 137-144 (1997).

95 Janert, P. K. \& Schick, M. Phase behavior of ternary homopolymer/diblock blends: microphase unbinding in the symmetric system. Macromolecules 30, 3916-3920 (1997).

96 Lipowsky, R. \& Leibler, S. Unbinding transitions of interacting membranes. Phys. Rev. Lett. 56, 2541-2544 (1986).

97 Hornreich, R. M., Luban, M. \& Shtrikman, S. Critical behavior at onset of K-space instability on $\lambda$-line. Phys. Rev. Lett. 35, 1678-1681 (1975).

98 Broseta, D. \& Fredrickson, G. H. Phase equilibria in copolymer/homopolymer ternary blends: molecular weight effects. J. Chem. Phys. 93, 2927-2938 (1990).

99 Kielhorn, L. \& Muthukumar, M. Fluctuation theory of diblock copolymer/homopolymer blends and its effects on the lifshitz point. J. Chem. Phys. 107, 5588-5608 (1997).

100 Fredrickson, G. H. \& Bates, F. S. Design of bicontinuous polymeric microemulsions. J. Polym. Sci. Polym. Phys. 35, 2775-2786 (1997)

101 Hillmyer, M. A., Maurer, W. W., Lodge, T. P., Bates, F. S. \& Almdal, K. Model bicontinuous microemulsions in ternary homopolymer/block copolymer blends. J. Phys. Chem. B 103, 4814-4824 (1999).

102 Maurer, W. W., Bates, F. S., Lodge, T. P., Almdal, K., Mortensen, K. \& Fredrickson, G. H. Can a single function for $\chi$ account for block copolymer and homopolymer blend phase behavior? J. Chem. Phys. 108, 2989-3000 (1998).

103 Zhou, N., Bates, F. S. \& Lodge, T. P. Mesoporous membrane templated by a polymeric bicontinuous microemulsion. Nano Lett. 6, 2354-2357 (2006).

104 Zhou, N. Polymeric Bicontinuous Microemulsions. PhD thesis, Univ. Minnesota (2007).

105 Rachapudy, H., Smith, G. G., Raju, V. R. \& Graessley, W. W. Properties of amorphous and crystallizable hydrocarbon polymers. 3. Studies of the hydrogenation of polybutadiene. J. Polym. Sci. Polym. Phys. 17, 1211-1222 (1979).

106 Gotro, J. T. \& Graessley, W. W. Model hydrocarbon polymers: rheological properties of linear polyisoprenes and hydrogenated polyisoprenes. Macromolecules 17, 2767-2775 (1984).

107 Khandpur, A. K., Macosko, C. W. \& Bates, F. S. Transmission electron microscopy of saturated hydrocarbon block copolymers. J. Polym. Sci. Polym. Phys. 33, 247-252 (1995).

108 Khandpur, A. K. Block Copolymers: Phase Behavior and Compatibilization of Polymer Blends. PhD thesis, Univ. Minnesota (1995).

109 Jones, B. H. Polymeric Bicontinuous Microemulsions as Templates for Nanostructured Materials. PhD thesis, Univ. Minnesota (2011).

110 Hamley, I. W., Fairclough, J. P. A., Terrill, N. J., Ryan, A. J., Lipic, P. M., Bates, F. S. \& Towns-Andrews, E. Crystallization in oriented semicrystalline diblock copolymers. Macromolecules 29, 8835-8843 (1996).

111 Roque-Malherbe, R. M. A. Adsorption and Diffusion in Nanoporous Materials (Taylor and Francis Group, Boca Raton, 2007).

112 Barrett, E. P., Joyner, L. G. \& Halenda, P. P. The determination of pore volume and area distributions in porous substances. J. Am. Chem. Soc. 73, 373-380 (1951).

113 Brun, M., Lallemand, A., Quinson, J.- F. \& Eyraud, C. A new method for the simultaneous determination of the size and shape of pores: the thermoporometry. Thermochim. Acta 21, 59-88 (1977).

114 Landry, M. R. Thermoporometry by differential scanning calorimetry: experimental considerations and applications. Thermochim. Acta 433, 27-50 (2005).

115 Nguyen, A. M. \& Irgum, K. Epoxy-based monoliths. A novel hydrophilic separation material for liquid chromatography of biomolecules. Chem. Mater. 18, 6308-6315 (2006).

116 Hedrick, J. L., Russell, T. P., Labadie, J., Lucas, M. \& Swanson, S. High temperature nanofoams derived from rigid and semi-rigid polyimides. Polymer 36, 2685-2697 (1995).

117 Kiefer, J., Hilborn, J. G., Hedrick, J. L., Cha, H. J., Yoon, D. Y. \& Hedrick, J. C. Microporous cyanurate networks via chemically induced phase separation. Macromolecules 29, 8546-8548 (1996).

118 Jahromi, S. \& Mostert, B. Templating nanoporosity in polyorganosilicates using reactive dendrimers. Macromolecules 37, 2159-2162 (2004).

$119 \mathrm{Ai}, \mathrm{H} ., \mathrm{Xu}, \mathrm{K}$. , Chen, W., Liu, H. \& Chen, M. Effect of non-reactive solvent on the formation and properties of porous epoxy thermosets formed via reaction-induced phase separation. Polym. Int. 58, 105-111 (2009).

120 Chung, S. E., Park, C. H., Yu, W.- R. \& Kang, T. J. Thermoresponsive shape memory characteristics of polyurethane electrospun web. J. Appl. Polym. Sci. 120, 492-500 (2011).

121 Jonas, F., Heywang, G., Schmidtberg, W., Heinze, J. \& Dietrich, M. Process for the preparation of polythiophenes. European patent 339340 (1989).

122 Jonas, F. \& Schrader, L. Conductive modifications of polymers with polypyrroles and polythiophenes. Synth. Met. 41-43, 831-836 (1991).

123 Carter, S. A., Angelopoulos, M., Karg, S., Brock, P. J. \& Scott, J. C. Polymeric anodes for improved polymer light-emitting diode performance. Appl. Phys. Lett. 70, 2067-2069 (1997).

124 Groenendaal, L., Jonas, F., Freitag, D., Pielartzik, H. \& Reynolds, J. R. Poly(3,4ethylenedioxythiophene) and its derivatives: past, present, and future. Adv. Mater. 12, 481-494 (2000)
125 Sirringhaus, H., Kawase, T., Friend, R. H., Shimoda, T., Inbasekaran, M., Wu, W. \& Woo, E. P. High-resolution inkjet printing of all-polymer transistor circuits. Science 290, 2123-2136 (2000).

126 Kim, W. H., Makinen, A. J., Nikolov, N., Shashidhar, R., Kim, H. \& Kafafi, Z. H. Molecular organic light-emitting diodes using highly conducting polymers as anodes. Appl. Phys. Lett. 80, 3844-3846 (2002).

127 Kirchmeyer, S. \& Reuter, K. Scientific importance, properties and growing applications of poly(3,4-ethylenedioxythiophene). J. Mater. Chem. 15, $2077-2088$ (2005).

$128 \mathrm{Na}$, S.- I., Kim, S.- S., Jo, J. \& Kim, D.- Y. Efficient and flexible ITO-free organic solar cells using highly conductive polymer anodes. Adv. Mater. 20, 4061-4067 (2008).

129 Cho, J. H., Lee, J., Xia, Y., Kim, B., He, Y., Renn, M. J., Lodge, T. P. \& Frisbie, C. D. Printable ion-gel gate dielectrics for low-voltage polymer thin-film transistors on plastic. Nat. Mater. 7, 900-906 (2008).

130 Stein, R., Kogler, F. R. \& Brabec, C. J. Interface materials for organic solar cells. J. Mater. Chem. 20, 2499-2512 (2010).

131 Cooper, A. I. Conjugated microporous polymers. Adv. Mater. 21, 1291-1295 (2009).

132 Winther-Jensen, B., Winther-Jensen, O., Forsyth, M. \& MacFarlane, D. R. High rates of oxygen reduction over a vapor phase-polymerized PEDOT electrode. Science $\mathbf{3 2 1}$, 671-674 (2008).

133 Ahmad, S., Yum, J.- H., Xianxi, Z., Grätzel, M., Butt, H.- J. \& Nazeeruddin, M. K. Dyesensitized solar cells based on poly(3,4-ethylenedioxythiophene) counter electrode derived from ionic liquids. J. Mater. Chem. 20, 1654-1658 (2010).

134 Jones, B. H., Cheng, K.- Y., Holmes, R. J. \& Lodge, T. P. Nanoporous poly(3,4ethylenedioxythiophene) derived from polymeric bicontinuous microemulsion templates. Macromolecules doi:10.1021/ma202239b.

135 Pei, Q., Zuccarello, G., Ahlskog, M. \& Inganäs, O. Electrochromic and highly stable poly(3,4-ethylenedioxythiophene) switches between opaque blue-black and transparent sky blue. Polymer 35, 1347-1351 (1994).

136 de Leeuw, D. M., Kraakman, P. A., Bongaerts, P. F. G., Mutsaers, C. M. J. \& Klaassen, D. B. M. Electroplating of conductive polymers for the metallization of insulators. Synth. Met. 66, 263-273 (1994).

137 Ha, Y.- H., Nikolov, N., Pollack, S. K., Mastrangelo, J., Martin, B. D. \& Shashidhar, R. Towards a transparent, highly conductive poly(3,4-ethylenedioxythiophene). Adv. Funct. Mater. 14, 615-622 (2004).

138 Brunauer, S., Emmett, P. H. \& Teller, E. Adsorption of gases in multimolecular layers. J. Am. Chem. Soc. 60, 309-319 (1938).

139 Jones, B. H. \& Lodge, T. P. High-temperature nanoporous ceramic monolith prepared from a polymeric bicontinuous microemulsion template. J. Am. Chem. Soc. 131, 1676-1677 (2009)

140 Duguet, E., Schappacher, M. \& Soum, A. High molar mass polysilazane: a new polymer. Macromolecules 25, 4835-4839 (1992).

141 KiON Corporation. Technical Bulletin TB1: KiON Ceraset Polyureasilazane and KiON Ceraset Polysilazane 20 (KiON Corporation, Huntingdon Valley, PA, USA).

142 Davis, S. A., Burkett, S. L., Mendelson, N. H. \& Mann, S. Bacterial templating of ordered macrostructures in silica and silica-surfactant mesophases. Nature $\mathbf{3 8 5}$, 420-423 (1997).

143 Antonietti, M., Berton, B., Göltner, C. \& Hentze, H.- P. Synthesis of mesoporous silica with large pores and bimodal pore size distribution by templating of polymer latices. Adv. Mater. 10, 154-159 (1998).

144 Yang, P., Deng, T., Zhao, D., Feng, P., Pine, D., Chmelka, B. F., Whitesides, G. M. \& Stucky, G. D. Hierarchically ordered oxides. Science 282, 2244-2246 (1998).

145 Holland, B. T., Abrams, L. \& Stein, A. Dual templating of macroporous silicates with zeolitic microporous frameworks. J. Am. Chem. Soc. 121, 4308-4309 (1999).

146 Yin, J. S. \& Wang, Z. L. Plasmon energy shift in mesoporous and double length-scale ordered nanoporous silica. Appl. Phys. Lett. 74, 2629-2631 (1999).

147 Huang, L., Wang, Z., Sun, J., Miao, L., Li, Q., Yan, Y. \& Zhao, D. Fabrication of ordered porous structures by self-assembly of zeolite nanocrystals. J. Am. Chem. Soc. 122, 3530-3531 (2000).

148 Dong, A., Wang, Y., Tang, Y., Zhang, Y., Ren, N. \& Gao, Z. Mechanically stable zeolite monoliths with three-dimensional ordered macropores by the transformation of mesoporous silica spheres. Adv. Mater. 14, 1506-1510 (2002).

149 Sen, T., Tiddy, G. J. T., Casci, J. L. \& Anderson, M. W. One-pot synthesis of hierarchically ordered porous-silica materials with three orders of length scale. Angew. Chem. Int. Ed. 42, 4649-4653 (2003).

150 Zhou, Y. \& Antonietti, M. A novel tailored bimodal porous silica with well-defined inverse opal microstructure and super-microporous lamellar nanostructure. Chem. Commun. 2564-2565 (2003).

151 Kuang, D., Brezesinski, T. \& Smarsly, B. Hierarchical porous silica materials with a trimodal pore system using surfactant templates. J. Am. Chem. Soc. 126, 10534-10535 (2004).

152 Fan, W., Snyder, M. A., Kumar, S., Lee, P.- S., Yoo, W. C., McCormick, A. V., Penn, R. L., Stein, A. \& Tsapatsis, M. Hierarchical nanofabrication of microporous crystals with ordered mesoporosity. Nat. Mater. 7, 984-991 (2008).

153 Zhang, S., Chen, L., Zhou, S., Zhao, D. \& Wu, L. Facile synthesis of hierarchically ordered porous carbon via in situ self-assembly of colloidal polymer and silica spheres and its use as a catalyst support. Chem. Mater. 22, 3433-3440 (2010).

154 Zhao, B. \& Collinson, M. M. Well-defined hierarchical templates for multimodal porous material fabrication. Chem. Mater. 22, 4312-4319 (2010).

155 Yang, D., Qi, L. \& Ma, J. Eggshell membrane templating of hierarchically ordered macroporous networks composed of $\mathrm{TiO}_{2}$ tubes. Adv. Mater. 14, 1543-1546 (2002).

156 Yang, D., Qi, L. \& Ma, J. Hierarchically ordered networks comprising crystalline $\mathrm{ZrO}_{2}$ tubes though sol-gel mineralization of eggshell membranes. J. Mater. Chem. 13, $1119-1123$ (2003) 
157 Shin, Y., Liu, J., Chang, J. H., Nie, Z. \& Exarhos, G. Hierarchically ordered ceramics through surfactant-templated sol-gel mineralization of biological cellular structures. Adv. Mater. 13, 728-732 (2001).

158 Lee, Y.- J., Lee, J. S., Park, Y. S. \& Yoon, K. B. Synthesis of large monolithic zeolite foams with variable macropore architectures. Adv. Mater. 13, 1259-1263 (2001).

159 Lee, Y.- J. \& Yoon, K. B. Effect of composition of polyurethane foam template on the morphology of silicate foam. Micropor. Mesopor. Mater. 88, 176-186 (2006).

160 Li, L.- L., Duan, W.- T., Yuan, Q., Li, Z.- X., Duan, H.- H. \& Yan, C.- H. Hierarchical $\gamma-\mathrm{Al}_{2} \mathrm{O}_{3}$ monoliths with highly ordered $2 \mathrm{~d}$ hexagonal mesopores in macroporous walls. Chem. Commun. 6174-6176 (2009).

161 Wang, Y., Tang, Y., Dong, A., Wang, X., Ren, N., Shan, W. \& Gao, Z. Self-supporting porous zeolite membranes with sponge-like architecture and zeolitic microtubes. Adv. Mater. 14, 994-997 (2002).

162 Drisko, G. L., Cao, L., Kimling, M. C., Harrisson, S., Luca, V. \& Caruso, R. A. Pore size and volume effects on the incorporation of polymer into macro- and mesoporous zirconium titanium oxide membranes. ACS Appl. Mater. Interf. 1, 2893-2901 (2009).

163 Zhang, B., Davis, S. A. \& Mann, S. Starch gel templating of spongelike macroporous silicate monoliths and mesoporous films. Chem. Mater. 14, 1369-1375 (2002)

164 Wang, H., Huang, L., Wang, Z., Mitra, A. \& Yan, Y. Hierarchical zeolite structures with designed shape by gel-casting of colloidal nanocrystal suspensions. Chem. Commun. 1364-1365 (2001).

165 Liang, C., Dai, S. \& Guiochon, G. Use of gel-casting to prepare HPLC monolithic silica columns with uniform mesopores and tunable macrochannels. Chem. Commun. 2680-2681 (2002).

166 Drisko, G. L., Luca, V., Sizgek, E., Scales, N. \& Caruso, R. A. Template synthesis and adsorption properties of hierarchically porous zirconium titanium oxides. Langmuir 25, 5286-5293 (2009)

167 Jacobsen, C. J. H., Madsen, C., Houzvicka, J., Schmidt, I. \& Carlsson, A. Mesoporous zeolite single crystals. J. Am. Chem. Soc. 122, 7116-7117 (2000).

168 Tao, Y., Kanoh, H. \& Kaneko, K. ZSM-5 monolith of uniform mesoporous channels. J. Am. Chem. Soc. 125, 6044-6045 (2003).

169 Li, W.- C., Lu, A.- H., Palkovits, R., Schmidt, W., Spliethoff, B. \& Schüth, F. Hierarchically structured monolithic silicalite-1 consisting of crystallized nanoparticles and its performance in the Beckmann rearrangement of cyclohexanone oxime. J. Am. Chem. Soc. 127, 12595-12600 (2005).

170 Minakuchi, H., Nakanishi, K., Soga, N., Ishizuka, N. \& Tanaka, N. Octadecylsilylated porous silica rods as separation media for reversed-phase liquid chromatography. Anal. Chem. 68, 3498-3501 (1996).

171 Nakanishi, K. Pore structure control of silica gels based on phase separation. J. Porous Mater. 4, 67-112 (1997).

172 Zhao, D., Yang, P., Chmelka, B. F. \& Stucky, G. D. Multiphase assembly of mesoporous-macroporous membranes. Chem. Mater. 11, 1174-1178 (1999).

173 Nakanishi, K., Takahashi, R., Nagakane, T., Kitayama, K., Koheiya, N., Shikata, H. \& Soga, N. Formation of hierarchical pore structure in silica gel. J. Sol-Gel Sci. Technol. 17, 191-210 (2000)

174 Nakamura, N., Takahashi, R., Sato, S., Sodesawa, T. \& Yoshida, S. Ni/SiO 2 catalyst with hierarchical pore structure prepared by phase separation in sol-gel process. Phys. Chem. Chem. Phys. 2, 4983-4990 (2000).

175 Smått, J.- H., Schunk, S. \& Lindén, M. Versatile double-templating synthesis route to silica monoliths exhibiting a multimodal hierarchical porosity. Chem. Mater. 15, 2354-2361 (2003).

176 Lu, A.- H., Smått, J.- H., Backlund, S. \& Lindén, M. Easy and flexible preparation of nanocasted carbon monoliths exhibiting a multimodal hierarchical porosity. Micropor. Mesopor. Mater. 72, 59-65 (2004)

177 Brandhuber, D., Torma, V., Raab, C., Peterlik, H., Kulak, A. \& Hüsing, N. Glycolmodified silanes in the synthesis of mesoscopically organized silica monoliths with hierarchical porosity. Chem. Mater. 17, 4262-4271 (2005).

178 Smått, J.- H., Weidenthaler, C., Rosenholm, J. B. \& Lindén, M. Hierarchically porous metal oxide monoliths prepared by the nanocasting route. Chem. Mater. 18, 1443-1450 (2006).

179 Konishi, J., Fujita, K., Nakanishi, K. \& Hirao, K. Phase-separation-induced titania monoliths with well-defined macropores and mesostructured framework from colloidderived sol-gel systems. Chem. Mater. 18, 864-866 (2006).

180 Konishi, J., Fujita, K., Nakanishi, K. \& Hirao, K. Monolithic $\mathrm{TiO}_{2}$ with controlled multiscale porosity via a template-free sol-gel process accompanied by phase separation. Chem. Mater. 18, 6069-6074 (2006).

181 Wang, H. \& Pinnavaia, T. J. MFI zeolite with small and uniform intracrystal mesopores. Adv. Mater. 45, 7603-7606 (2006).

182 Sakatani, Y., Boissière, C., Grosso, D., Nicole, L., Soler-IIlia, G. J. A. A. \& Sanchez, C. Coupling nanobuilding block and breath figures approaches for the designed construction of hierarchically templated porous materials and membranes. Chem. Mater. 20, 1049-1056 (2008).

183 Huang, Y., Cai, H., Feng, D., Gu, D., Deng, Y., Tu, B., Wang, H., Webley, P. A. \& Zhao, D. One-step hydrothermal synthesis of ordered mesostructured carbonaceous monoliths with hierarchical porosities. Chem. Commun. 2641-2643 (2008).

184 Hasegawa, G., Kanamori, K., Nakanishi, K. \& Hanada, T. Facile preparation of hierarchically porous $\mathrm{TiO}_{2}$ monoliths. J. Am. Ceram. Soc. 93, 3110-3115 (2010).

185 Drisko, G. L., Zelcer, A., Luca, V., Caruso, R. A., Soler-Illia, G. J. A. A. One-pot synthesis of hierarchically structured ceramic monoliths with adjustable porosity. Chem. Mater. 22, 4379-4385 (2010).

186 Lee, M. N. \& Mohraz, A. Bicontinuous macroporous materials from Bijel templates. Adv. Mater. 22, 4836-4841 (2010).
187 Lee, M. N. \& Mohraz, A. Hierarchically porous silver monoliths from colloidal bicontinuous interfacially jammed emulsion gels. J. Am. Chem. Soc. 133, 6945-6947 (2011).

188 Hayakawa, T. \& Horiuchi, S. From angstroms to micrometers: self-organized hierarchical structure within a polymer film. Angew. Chem. Int. Ed. 42, 2285-2289 (2003).

189 Ikkala, O. \& ten Brinke, G. Hierarchical self-assembly in polymeric complexes: towards functional materials. Chem. Commun. 2131-2137 (2004).

190 ten Brinke, G., Ruokolainen, J. \& Ikkala, O. Supramolecular materials based on hydrgen-bonded polymers. Adv. Polym. Sci. 207, 113-177 (2007).

191 Valkama, S., Nykanen, A., Kosonen, H., Ramani, R., Tuomisto, F., Engelhardt, P., ten Brinke, G., Ikkala, O. \& Ruokolainen, J. Hierarchical porosity in self-assembled polymers: post-modification of block copolymer-phenolic resin complexes by pyrolysis allows the control of micro- and mesoporosity. Adv. Funct. Mater. 17, 183-190 (2007).

192 Matsushita, Y. Creation of hierarchically ordered nanophase structures in block polymers having various competing interactions. Macromolecules 40, 771-776 (2007).

193 Hammond, M. R. \& Mezzenga, R. Supramolecular routes towards liquid crystalline side-chain polymers. Soft Matter 4, 952-961 (2008).

194 Li, C., Schlüter, A. D., Zhang, A. \& Mezzenga, R. A new level of hierarchical structure control by use of supramolecular self-assembled dendronized block copolymers. Adv. Mater. 20, 4530-4534 (2008).

195 Tenneti, K. K., Chen, X., Li, C. Y., Wan, X., Fan, X., Zhou, Q.- F., Rong, L. \& Hsiao, B. $\mathrm{S}$. Competition between liquid crystallinity and block copolymer self-assembly in coreshell rod-coil block copolymers. Soft Matter 4, 458-461 (2008).

196 Hammond, M. R., Li, C., Tsitsilianis, C. \& Mezzenga, R. Hierarchical self-organization in polyelectrolyte-surfactant complexes based on heteroarm star block copolyampholytes. Soft Matter 5, 2371-2377 (2009).

197 Bolognesi, A., Galeotti, F., Giovanella, U., Bertini, F. \& Yunus, S. Nanophase separation in polystyrene-polyfluorene block copolymers thin films prepared through the breath figure procedure. Langmuir 25, 5333-5338 (2009).

198 Muñoz-Bonilla, A., Ibarboure, E., Papon, E. \& Rodriguez-Hernandez, J. Self-organized hierarchical structures in polymer surfaces: self-assembled nanostructures within breath figures. Langmuir 25, 6493-6499 (2009).

199 Matsushita, Y., Takano, A., Hayashida, K., Asari, T. \& Noro, A. Hierarchical nanophase-separated structures created by precisely-designed polymers with complexity. Polymer 50, 2191-2203 (2009).

200 Chen, X.- F., Shen, Z., Wan, X.- H., Fan, X.- H., Chen, E.- Q., Ma, Y. \& Zhou, Q.- F. Mesogen-jacketed liquid crystalline polymers. Chem. Soc. Rev. 39, 3072-3101 (2010).

$201 \mathrm{Hu}$, D., Xu, Z., Zeng, K. \& Zheng, S. From self-organized novolac resins to ordered nanoporous carbons. Macromolecules 43, 2960-2969 (2010).

202 Escalé, P., Save, M., Lapp, A., Rubatat, L. \& Billon, L. Hierarchical structures based on self-assembled diblock copolymers within honeycomb micro-structured porous films. Soft Matter 6, 3202-3210 (2010).

203 Escalé, P., Rubatat, L., Derail, C., Save, M. \& Billon, L. pH sensitive hierarchically self-organized bioinspired films. Macromol. Rapid Commun. 32, 1072-1076 (2011).

204 Zhou, Y., Schattka, J. H. \& Antonietti, M. Room-temperature ionic liquids as template to monolithic mesoporous silica with wormlike pores via a sol-gel nanocasting technique. Nano Lett. 4, 477-481 (2004).

205 Jones, B. H. \& Lodge, T. P. Hierarchically porous silica prepared from ionic liquid and polymeric bicontinuous microemulsion templates. Chem. Mater. 23, 4824-4831 (2011).

206 Jones, B. H. \& Lodge, T. P. Hierarchically structured materials from block polymer confinement within bicontinuous microemulsion-derived nanoporous polyethylene. ACS Nano 5, 8914-8927 (2011).

207 Bates, F. S., Rosedale, J. H., Stepanek, P., Lodge, T. P., Wiltzius, P., Fredrickson, G. H. \& Hjelm Jr, R. P. Static and dynamic crossover in a critical polymer mixture. Phys. Rev. Lett. 65, 1893-1896 (1990).

208 Funaki, Y., Kumano, K., Nakao, T., Jinnai, H., Yoshida, H., Kimishima, K., Tsutsumi, K., Hirokawa, Y. \& Hashimoto, T. Influence of casting solvents on microphaseseparated structures of poly(2-vinylpyridine)-block-polyisoprene. Polymer 40, 7147-7156 (1999).

209 Park, I., Park, S., Park, H.- W., Chang, T., Yang, H. \& Ryu, C. Y. Unexpected hexagonally perforated layer morphology of PS-b-PMMA block copolymer in supported thin film. Macromolecules 39, 315-318 (2006).

210 Stewart-Sloan, C. R. \& Thomas, E. L. Interplay of symmetries of block polymers and confining geometries. Eur. Polym. J. 47, 630-646 (2011).

211 Wu, Y., Cheng, G., Katsov, K., Sides, S. W., Wang, J., Tang, J., Fredrickson, G. H., Moskovits, M. \& Stucky, G. D. Composite mesostructures by nano-confinement. Nat. Mater. 3, 816-822 (2004).

212 Xiang, H., Shin, K., Kim, T., Moon, S. I., McCarthy, T. J. \& Russell, T. P. Block copolymers under cylindrical confinement. Macromolecules 37, 5660-5664 (2004).

213 Shin, K., Xiang, H., Moon, S. I., Kim, T., McCarthy, T. J. \& Russell, T. P. Curving and frustrating flatland. Science 306, 76 (2004).

214 Xiang, H., Shin, K., Kim, T., Moon, S. I., McCarthy, T. J. \& Russell, T. P. From cylinders to helices upon confinement. Macromolecules 38, 1055-1056 (2005).

215 Xiang, H., Shin, K., Kim, T., Moon, S., McCarthy, T. J. \& Russell, T. P. The influence of confinement and curvature on the morphology of block copolymers. J. Polym. Sci. Polym. Phys. 43, 3377-3383 (2005). 
216 Sun, Y., Steinhart, M., Zschech, D., Adhikari, R., Michler, G. H. \& Gösele, U. Diameter-dependence of the morphology of PS-b-PMMA nanorods confined within ordered porous alumina templates. Macromol. Rapid Commun. 26, 369-375 (2005).

217 Wang, Y., Gösele, U. \& Steinhart, M. Mesoporous polymer nanofibers by infiltration of block copolymers with sacrificial domains into porous alumina. Chem. Mater. 20, 379-381 (2008)

218 Wang, Y., Gösele, U. \& Steinhart, M. Mesoporous block copolymer nanorods by swelling-induced morphology reconstruction. Nano Lett. 8, 3548-3553 (2008).

219 Dobriyal, P., Xiang, H., Kazuyuki, M., Chen, J.- T., Jinnai, H. \& Russell, T. P. Cylindrically confined diblock copolymers. Macromolecules 42, 9082-9088 (2009).
220 Jeon, S.- M., Lee, Y., Kim, J.- H., Lee, J.- K., Char, K. \& Sohn, B.- H. Internal morphologies of diblock copolymer nanorods fabricated from regular and irregular pores of anodized aluminum oxide templates. React. Funct. Polym. 69, 558-563 (2009).

221 Pulamagatta, B., Yau, M. Y. E., Gunkel, I., Thurn-Albrecht, T., Schröter, K., Pfefferkorn, D., Kressler, J., Steinhart, M. \& Binder, W. H. Block copolymer nanotubes by melt-infiltration of nanoporous aluminum oxide. Adv. Mater. 23, 781-786 (2011).

222 Wang, Y., Tong, L. \& Steinhart, M. Swelling-induced morphology reconstruction in block copolymer nanorods: kinetics and impact of surface tension during solvent evaporation. ACS Nano 5, 1928-1938 (2011). 